San Jose State University

SJSU ScholarWorks

Master's Theses

Master's Theses and Graduate Research

1995

\title{
Synthesis and characterization of liquid crystal-like stationary phases for high performance liquid chromatography
}

Zhuxu Wang

San Jose State University

Follow this and additional works at: https://scholarworks.sjsu.edu/etd_theses

\section{Recommended Citation}

Wang, Zhuxu, "Synthesis and characterization of liquid crystal-like stationary phases for high performance liquid chromatography" (1995). Master's Theses. 1038.

DOI: https://doi.org/10.31979/etd.fsqp-83vp

https://scholarworks.sjsu.edu/etd_theses/1038

This Thesis is brought to you for free and open access by the Master's Theses and Graduate Research at SJSU ScholarWorks. It has been accepted for inclusion in Master's Theses by an authorized administrator of SJSU ScholarWorks. For more information, please contact scholarworks@sjsu.edu. 


\section{INFORMATION TO USERS}

This manuscript has been reproduced from the microfilm master. UMI films the text directly from the original or copy submitted. Thus, some thesis and dissertation copies are in typewriter face, while others may be from any type of computer printer.

The quality of this reproduction is dependent upon the quality of the copy submitted. Broken or indistinct print, colored or poor quality illustrations and photographs, print bleedthrough, substandard margins, and improper alignment can adversely affect reproduction.

In the unlikely event that the author did not send UMI a complete manuscript and there are missing pages, these will be noted. Also, if unauthorized copyright material had to be removed, a note will indicate the deletion.

Oversize materials (e.g., maps, drawings, charts) are reproduced by sectioning the original, beginning at the upper left-hand corner and contimuing from left to right in equal sections with small overlaps. Each original is also photographed in one exposure and is included in reduced form at the back of the book.

Photographs included in the original manuscript have been reproduced xerographically in this copy. Higher quality $6^{n} \times 9^{n}$ black and white photographic prints are available for any photographs or illustrations appearing in this copy for an additional charge. Contact UMI directly to order.

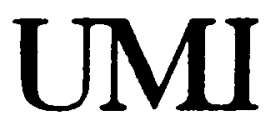

A Bell \& Howell information Company 300 North Zeeb Road. Ann Afbor. MI 48106-1346 USA 313:761-4700 800:521-0600 


$$
\text { - -. }
$$




\title{
SYNTHESIS AND CHARACTERIZATION \\ OF LIQUID CRYSTAL-LIKE STATIONARY PHASES \\ FOR HIGH PERFORMANCE LIQUID CHROMATOGRAPHY
}

\author{
A Thesis \\ Presented to \\ The Faculty of The Department of Chemistry \\ San Jose State University
}

\author{
In Partial Fulfillment \\ of the Requirement for the Degree \\ Master of Science
}

by

Zhuxu Wang

May, 1995 
UMI Number: 1374629

UMI Microform 1374629

Copyright 1995, by UuI Company. All rights reserved.

This microform edition is protected against unauthorized copying under Title 17, United States Code.

\section{UMI}

300 North Zeeb Road

Ann Arbor, MI 48103 
(C) 1995

Zhuxu Wang

ALL RIGHTS RESERVED 
APPROVED FOR THE DEPARTMENT OF CHEMISTRY

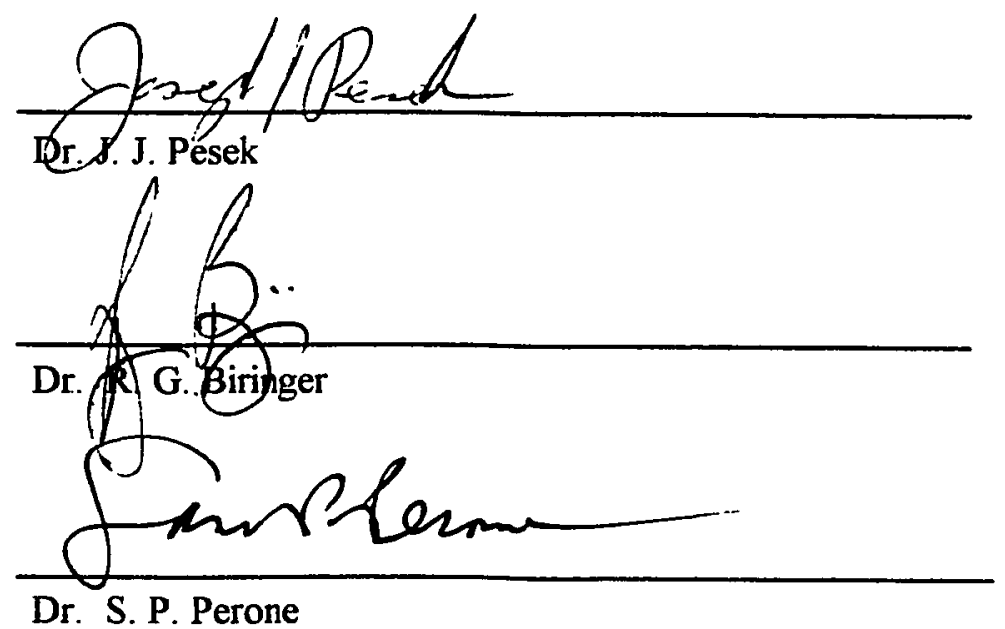

APPROVED FOR THE UNIVERSITY

Elerene Sir. vitanfore. 


\section{ABSTRACT \\ SYNTHESIS AND CHARACTERIZATION \\ OF LIQUID CRYSTAL-LIKE STATIONARY PHASES FOR \\ HIGH PERFORMANCE LIQUID CHROMATOGRAPHY}

\section{by Zhuxu Wang}

A liquid crystal-like bonded stationary phase for use in high-performance liquid chromatography (HPLC) is described and discussed. The bonded phase is prepared by hydrosilation at the terminal double bond of 4-methoxyphenyl 4-allyloxybenzoate (MPAB) and cholesteryl 10-undecenoate. An optimum surface coverage is obtained by different catalytic systems, ratio of olefin-silica and catalyst-silica, reaction time, and reaction temperature. Differential scanning calorimetry (DSC), diffuse-reflectance, infrared, Fourier-transform spectroscopy (DRIFT), and ${ }^{29} \mathrm{Si}$ cross-polarization, magic-anglespinning nuclear magnetic resonance spectroscopy (CP-MAS NMR) of the two bonded phases confirmed that the reaction was successful. Carbon elemental analysis showed a high loading of the liquid crystal-like on the silica surface. Initial chromatographic studies of the separation of a complex mixture of polycyclic aromatic hydrocarbons (PAHs) show the promise of this bonded stationary phase for the separation of structural isomers under reverse-phase conditions. 


\section{ACKNOWLEDGEMENTS}

I would like to thank Dr. Joseph J. Pesek for his trusting and advice during this work. Also, I would like to give my thanks to Dr. Roger G. Biringer and Dr. Sam Perone for being part of my graduate committee members. A special thank is given to Dr. Eric J. Willamsen for his patient guidance and assistance throughout my research and for his reading and valuable suggestions for the entire manuscript. 
$\begin{array}{lll} & & \text { Page }\end{array}$

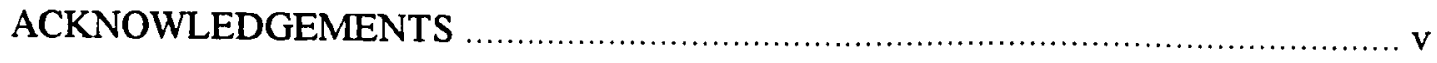

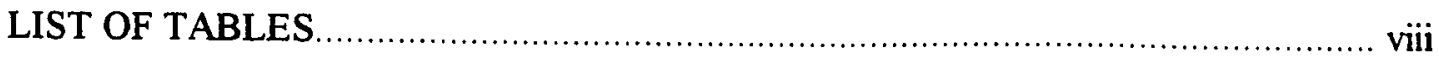

LIST OF FIGURES

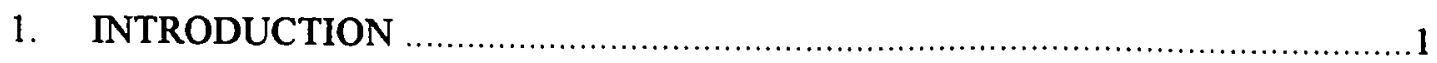

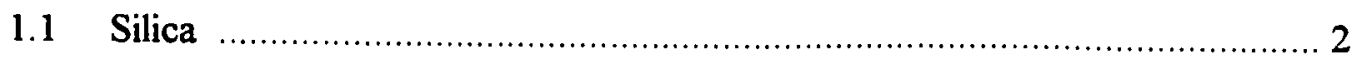

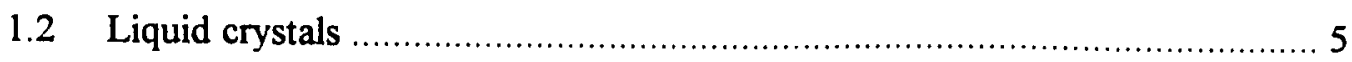

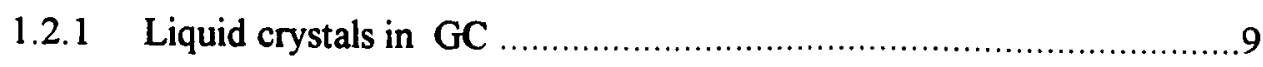

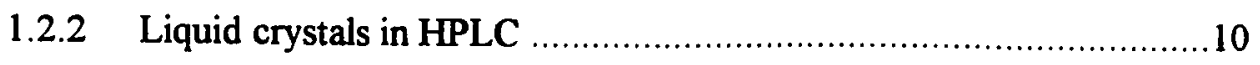

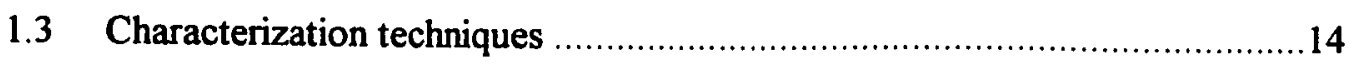

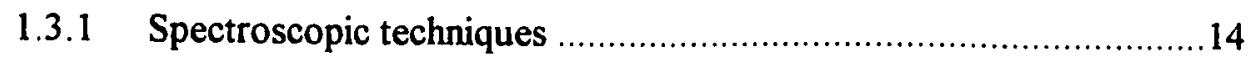

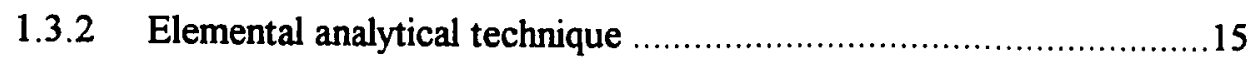

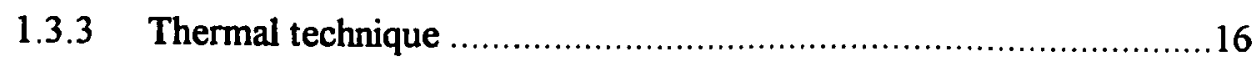

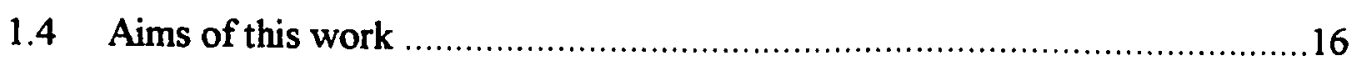

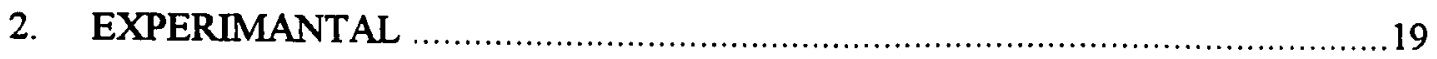

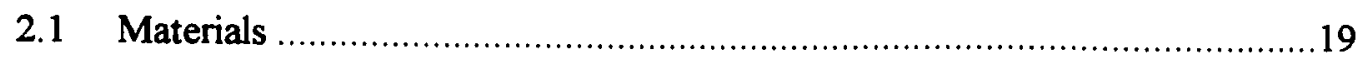

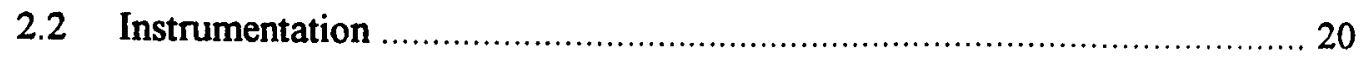

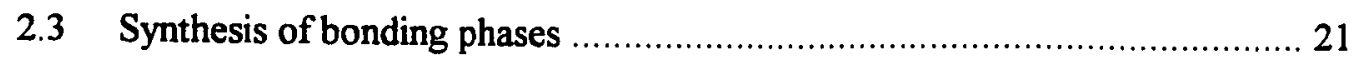

2.3.1 Synthesis of cholesteryl 10-undecenoate bonded on hydride silica .. 21

2.3.2 Synthesis of 4-methoxyphenyl 4-allyloxybenzoate bonded

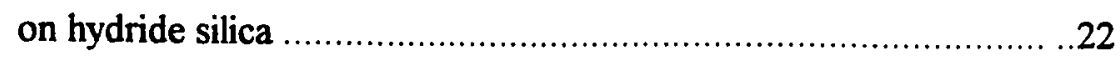

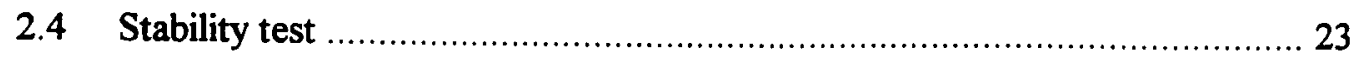

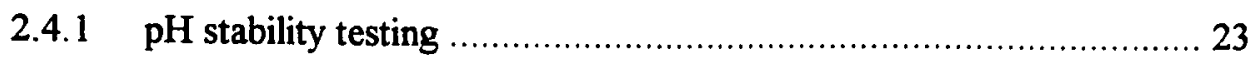

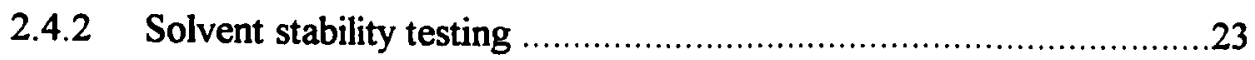




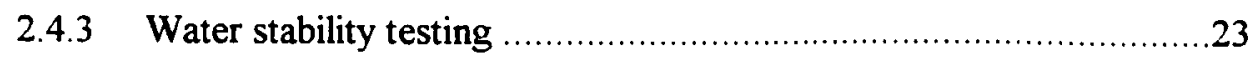

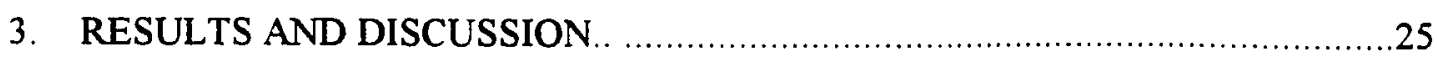

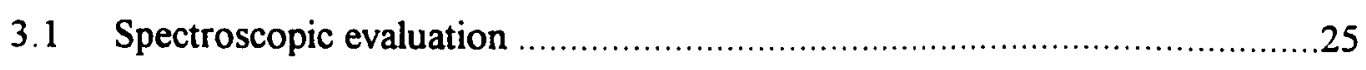

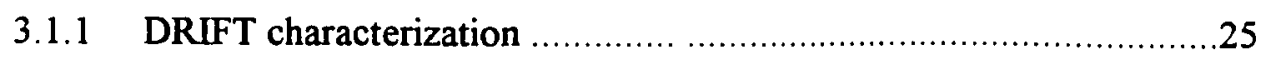

3.1.1.1 Silica hydride ...............................................25

3.1.1.2 Cholesteryl 10-undecenoate and bonded phase .............26

3.1.1.3 MPAB and bonded phase ..................................29

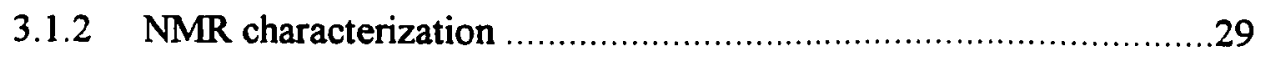

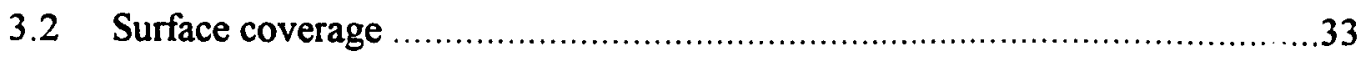

3.2.1 Effect of olefin to silica to catalyst ratio ....................................33

3.2.1.1 Change of catalyst concentration .............................33

3.2.1.2 Change of olefin concentration.................................35

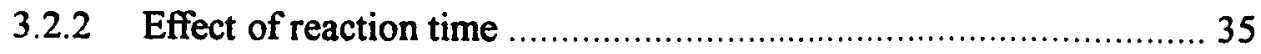

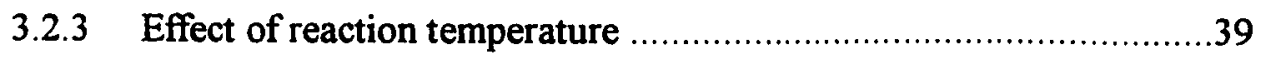

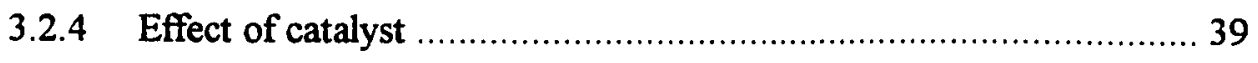

3.2.5 Suggested experiments condition .................................... 42

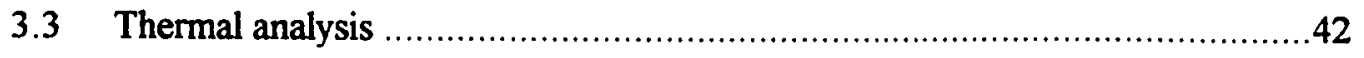

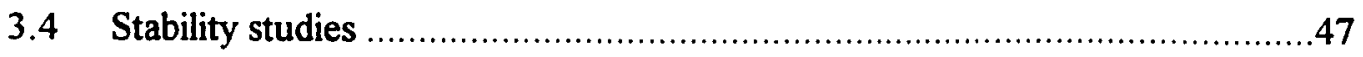

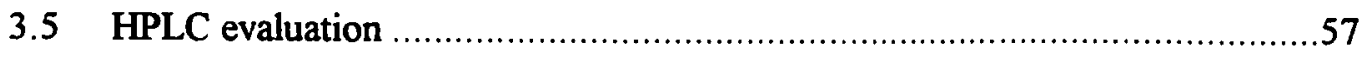

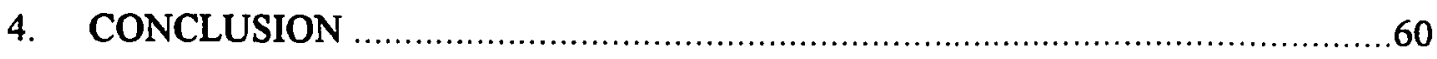

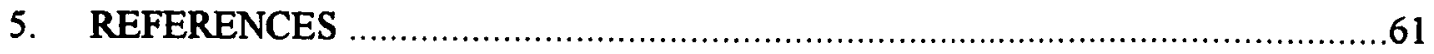




\section{LIST OF TABLES}

Table

1. Effect of catalyst concentration to surface coverage for cholesteryl

10-undecenoate and 4-methoxyphenyl 4-allyloxybenzoate bonded to silica .36

2. Surface coverage as a function of ratio of liquid crystal/silica for liquid crystals bonded to hydride silica 37

3. Effect of catalyst systems on surface coverage for the hydrosilation of liquid crystals on hydride silica

4. Effect of $\mathrm{pH}$ to surface coverage for cholesteryl 10-undecenoate bonded to hydride silica .52 


\section{LIST OF FIGURES}

Figures Page

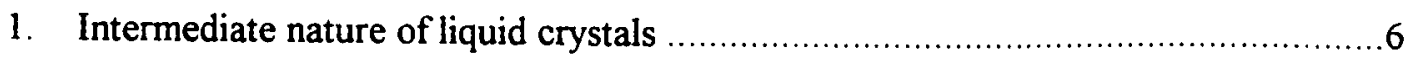

2. Schematic representation of the molecular arrangement in crystalline, nematic, isotropic, and cholesteric phases ................................................

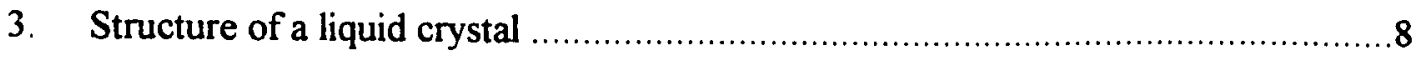

4. Schematic representation of the "slot model" for retention of molecular ...............10

5. Reaction scheme of the bonding or 4-(allyoxy)-4-methoxyphenyl

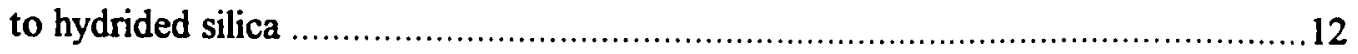

6. Reaction scheme for the synthesis of liquid crystallint stationary phases ..............13

7. Structure formula of the liquid crystals in this work ..................................... 18

8. Partial DRIFT spectrum of cholesteryl 10-undecenoate bonded to hydride silica: (A) hydride silica and (B) bonded phase ........................................27

9. DRIFT spectrum of cholesteryl 10-undecenoate .........................................28

10. DRIFT spectrum of 4-methoxyphenyl 4-allyloxybenzoate ..............................30

11. Partial DRIFT spectra of 4-methoxyphenyl 4-allyloxybenzoate bonded to silica: (A) hydride silica and (B) bonded phase 31

12. ${ }^{29} \mathrm{Si}$ CP-MAS NMR spectra of olefins bonded to silica: (A) hydride silica; (B) 4-methoxyphenyl 4-allyloxybenzoate; and (C) cholesteryl 10-undecenoate bonded to silica bonded to silica 32

13. Surface coverage as a function of catalyst concentration in bonded phases of 
(A) cholesteryl 10-undecenoate and (B) 4-methoxyphenyl 4-allyloxybenzoate........34

14. Effect of reaction time on surface coverage in bonded phases of (A)

cholesteryl 10-undecenoate and (B) 4-methoxyphenyl 4-allyloxybenzoate

15. Effect of reaction temperature on surface coverage in bonded phases of (A)

cholesteryl 10-undecenoate and (B) 4-methoxyphenyl 4-allyloxybenzoate

16. DRIFT spectra of cholesteryl 10-undecenoate bonded to hydrided silica in two different catalyst systems: in (A) Rh and (B) Ni catalyst system

17. DRIFT spectra of 4-methoxyphenyl 4-allyloxybenzoate bonded to hydrided

silica in (A) $\mathrm{Rh}$ and (B) Ni catalyst system

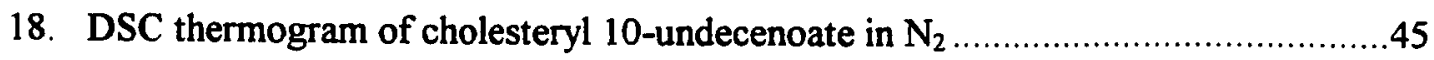

19. DSC thermogram of 4-methoxyphenyl 4-allyloxybenzoate in $\mathrm{N}_{2} \ldots \ldots \ldots \ldots \ldots \ldots \ldots \ldots \ldots$

20. DSC thermogram of hydride silica bonded with (A) cholesteryl

10-undecenoate and (B) 4-methoxyphenyl 4-allyloxybenzoate

21. DSC thermogram of silica hydride (A) and after bonding with (B) cholesteryl

10-undecenoate and (C) 4-methoxyphenyl 4-allyloxybenzoate in $\mathrm{O}_{2}$

22. Partial DRIFT spectra of hydride silica bonded with cholesteryl

10-undecenoate $(\mathrm{A})$ in $(\mathrm{B}) \mathrm{pH}=2.87$ and $(\mathrm{C}) \mathrm{pH}=7.96$

23. Surface coverage of cholesteryl 10-undecenoate-bonded hydride silica as a function of hydrolysis time in solvent testing

24. Partial DRIFT spectra of hydride silica bonded with cholesteryl 10-undecenoate

(A) after the hydrolysis testing for 120 hours in (B) solvent and (C) water .55

25. Surface coverage of cholesteryl 10-undecenoate-bonded to silica as a 
function of hydrolysis time in water

26. Chromatogram of the separation of three PAH compounds on the cholesteryl

10-undecanoate-bonded silica phase in HPLC

27. Chromatogram of the separation of sixteen PAH compounds on the cholesteryl

10-undecanoate-bonded silica phase in HPLC 


\section{INTRODUCTION}

High-performance liquid chromatography (HPLC) has become the most common instrumental separation technique in recent years. Because separation occurs due to interactions between the analyte and the mobile and/or stationary phases, the nature of these stationary and mobile phases can effect a better or more efficient separation.

To change separation efficiency, changing the mobile phase composition is often done, but it does not solve all problems due to the limits of the stationary phase. Therefore, a variety of stationary phases have been developed. Stationary phases have been developed for the separation of different classes of compounds utilizing a number of different mechanisms.

Most stationary phases consist of two parts: a solid support and a material that is chemically bonded to or physically absorbed on that support. Silica is the most commonly used support material, but other possibilities include alumina, carbon-covered zirconium, and various polymers. A number of materials have been chemically bonded to or physically coated on the silica; commonly used materials are the monomeric $C_{18}, C_{8}$, and cyanopropyl molecules. Physically coated materials are most often found in GC. Chemically bonded materials are required for HPLC due to the poor column durability observed for physically coated materials under the high pressure used. A number of these bonded organic moieties have been developed to improve separations that are not currently possible and also increase column durability. One new type of stationary phase, whose selectivity is mainly based on molecular shape, involves the bonding of liquid 
crystals to silica.

Physically coated liquid crystals have been used successfully as gas chromatography stationary phases for the separation of organic isomers, polynuclear aromatic hydrocarbons and optical isomers [1-4]. It has also been shown that certain liquid crystals or structurally similar compounds can retain or develop liquid-crystalline behavior when bonded to a polysiloxane backbone [5]. So, it is possible that similar compounds bonded to silica may have liquid-crystalline behavior.

\subsection{Silica}

Porous and particulate silica, a polymer of silicic acid, has been commercially available as a solid support for HPLC for a long time $[6,7,8]$. Silica particles with diameters of $10-40 \mu \mathrm{m}$ and pore sizes of $100-400 \AA$ are generally available. The advantages of silica include good mechanical strength, relatively narrow pore size distribution and appropriate particle sizes. Fine size reduces the eddy diffusion effect and shortens the diffusion process of solutes between a solute and the mobile phase. However, silica has several disadvantages. A heterogeneous surface with high energy limits silica applications due to the nonspecific interaction of some groups on the surface with many materials. The interaction between silanols ( $\equiv \mathrm{SiOH}$ ), which are the terminal groups at the surface, with polar compounds through strong hydrogen bond and dipole-dipole interactions leads to mixed retention mechanisms, peak tailing, and the loss of chromatographic resolution, particularly when basic solutes are involved [9]. A limitation of $\mathrm{pH}$ range affects its utilization (silica dissolubility at $\mathrm{pH}>8$ and hydrolysis at $\mathrm{pH}<2$ ). 
Many methods investigated to overcome these problems and to improve selectivity involve chemical modification of the silica surface. An esterification reaction between silanols and an alcohol to form a Si-O-C surface linkage has been described. These bonded phases are of little use due to their poor hydrolytic stability. A more popular method of preparing bonded phases has been to attach the organic moieties to silica to give Si-O-Si-C linkages. The most common approach is organosilanzation, by which an organic material is bonded to a hydroxylated silica surface to form a siloxane linkage:

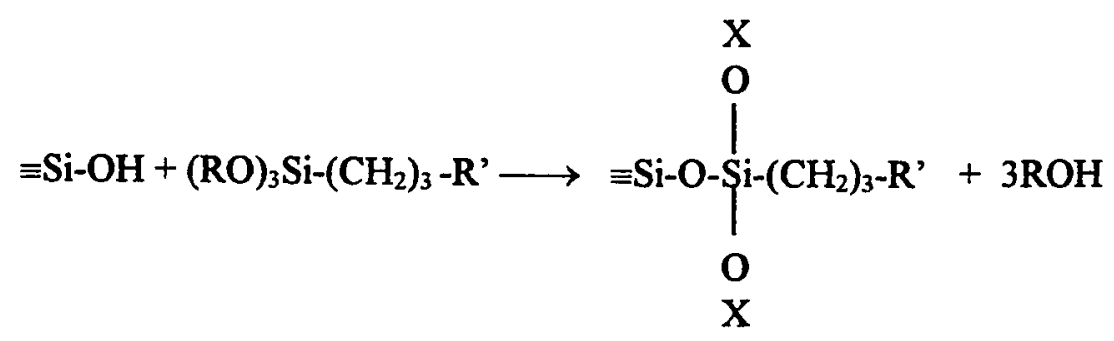

where $\mathrm{R}^{\prime}$ is a terminal group, $\mathrm{R}$ represents a methyl, or ethyl group, and $\mathrm{X}$ is $-\mathrm{H}$ or $-\mathrm{Si} \equiv$. This approach is similar to that employed in the so-called "silane coupling chemistry" [10]. This synthetic procedure is limited by the steric hindrance of the bonded organic group at the silica surface, which leads to higher concentration of unreacted surface silanols [11]. There also is the unsatisfactory hydrolytic stability of the siloxane linkage when mobile phases of high or low pH are used. These problems result in peak tailing in chromatography due to the interaction between the solute and the silica surface, and hence affect the separation efficiency. The formation of directly bonded organic moieties on silica to form Si-C linkage is known to produce more stable bonded phases $[11,12]$. One method to 
accomplish a direct Si-C linkage involves the reaction between a chlorinated silica surface and a Grignard or organolithium reagent $[13,14,15]$. The chlorination reaction scheme can be described by following two-step reaction sequence where $\mathrm{SOCl}_{2}$ is used as the chlorinating reagent and is followed by $\mathrm{Li}-\mathrm{R}$, an organolithium reagent:

$$
\begin{aligned}
& \equiv \mathrm{Si}-\mathrm{OH}+\mathrm{SOCl}_{2} \longrightarrow \equiv \mathrm{Si}-\mathrm{Cl}+\mathrm{HCl}+\mathrm{SO}_{2} \\
& \equiv \mathrm{Si}-\mathrm{Cl}+\mathrm{Li}-\mathrm{R} \longrightarrow \equiv \mathrm{Si}-\mathrm{R}+\mathrm{LiCl}
\end{aligned}
$$

This reaction pathway results in a direct silicon-carbon bond at the surface but produces undesirable salts $(\mathrm{LiCl})$ on the silica surface, which lead to nonuniform retention characteristics in the final product. However, more important is the fact that the reaction procedure is difficult to control because the organic group $\mathbf{R}$ must remain inert and intact during the preparation of the reagents.

Another possible method involves using a hydride intermediate to form Si-C linkages. The procedure involves reacting $\mathrm{SOCl}_{2}$ with the silica surface to form the chlorinated intermediate followed by reduction with lithium aluminum hydride as shown below [11]:

$$
\begin{aligned}
& \equiv \mathrm{Si}-\mathrm{OH}+\mathrm{SOCl}_{2} \longrightarrow \equiv \mathrm{Si}-\mathrm{Cl}+\mathrm{HCl}+\mathrm{SO}_{2} \\
& \equiv \mathrm{Si}-\mathrm{Cl}+\mathrm{LiAlH}_{4} \longrightarrow \quad \equiv \mathrm{Si}-\mathrm{H}+\mathrm{LiCl}+\mathrm{AlCl}_{3}
\end{aligned}
$$

Another synthetic route to produce the hydride intermediate is made by heterogeneous silanization [16]: 
$\equiv \mathrm{Si}-\mathrm{OH}+(\mathrm{RO})_{3} \mathrm{Si}-\mathrm{H} \stackrel{\mathrm{HCl}, \mathrm{H}_{2} \mathrm{O}}{\longrightarrow} \equiv \mathrm{Si}-\mathrm{O}-\mathrm{Si}-\mathrm{H}+3 \mathrm{ROH}$

The procedure involves the controlled deposition of a silane hydrolysis product to preferentially form an $\mathrm{Si}-\mathrm{H}$ monolayer on silica through the reaction of surface silanols at the central silicon atom of the silanizing reagent. The stability of silicon-hydrogen bonds has been well documented [16]. The H-group on silica surface can be utilized for further reaction with an organic material to form Si-C linkage.

$\equiv \mathrm{Si}-\mathrm{H}+\mathrm{CH}_{2}=\mathrm{CH}-\mathrm{R} \stackrel{\text { Catalyst }}{\longrightarrow} \equiv \mathrm{Si}-\mathrm{CH}_{2}-\mathrm{CH}_{2}-\mathrm{R}$

The Si-C linkages produced by olefin addition on a hydride-containing silica surface is known as hydrosilation. The reactions have resulted in a stable Si-C bond at the surface. The silica hydride can be used as a site for the attachment of other bonded moieties such as liquid crystals [17].

\subsection{Liquid crystals}

The liquid-crystalline phase, or mesophase, is a state of matter that is intermediate between a solid crystal and an anisotropic liquid. A liquid crystal flows like an ordinary fluid, but it has a higher degree of order than a liquid. Schematic representation of the liquid-crystalline materials as a function of temperature is shown in Figure 1 [18]. 


\begin{tabular}{l|l|r} 
crystalline & liquid & isotropic \\
solid & crystal & liquid \\
melting point & clearing point
\end{tabular}

Figure 1. Intermediate nature of liquid crystals. (Taken from ref. 18.)

When a substance in the liquid crystalline phase is heated to the melting point, the solid changes into a rather turbid liquid. Upon further heating a second transition point is reached where the turbid liquid becomes isotropic and consequently optically clear. The melting point and the clearing point define the temperature range in which the mesophase is thermodynamically stable [19]. This temperature ranges between $50-350^{\circ} \mathrm{C}$ for the majority of liquid crystals.

Because they are highly geometrically anisotropic in shape, liquid crystals are ordered and semi-rigid in their mesophase temperature-range $[19,20]$. One liquid crystal can have several types of ordering. The transitions between these different orderings can be caused by thermal processes (thermotropic mesomorphism) or by changes in solvent (lyotropic mesomorphism). Most liquid crystals used in stationary phases are affected by both temperature and solvent. Following the nomenclature originally proposed, thermotropic liquid crystals are classified into nematic, cholesteric, and smectic [Fig. 2].

The nematic liquid crystals differ from normal isotropic fluids only with respect to their long-range, orientational ordering. The preferred direction is usually parallel to a spatial axis. The cholesteric mesophase is a subset of the nematic group, but its preferred 


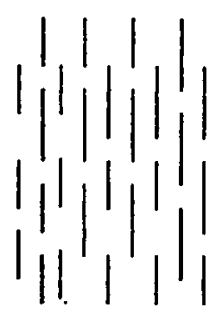

crystal
|IIIIIIII

|l|l||l||

|l|||||||

|l|l||l||

smectic A
|IIIIIIII

/III/I/II

/III/IIII

//I/I/I/I

smectic B

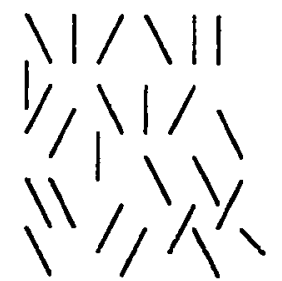

nematic

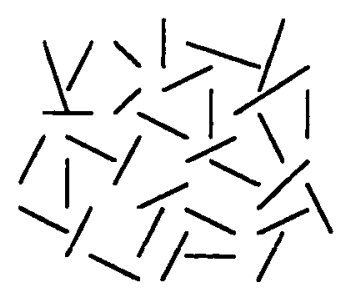

isotropic

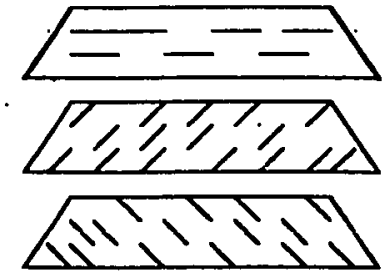

cholesteric

Figure 2. Schematic representation of the molecular arrangement in crystalline, nematic, isotropic, and cholesteric phases (taken from ref. 17). 
molecular direction is a spontaneous twist about an axis. Therefore, all cholesteric mesophases are optically active. Smectic liquid crystals are the most ordered mesophase, as they have stratified structures and a preferred direction. Depending on its molecular structure, the molecule may have one or more mesophases before it is transformed into an isotropic liquid. The temperature will affect the degree of ordering of the liquid crystal, with the more ordered smectic mesophase occurring at lower temperatures and the nematics occurring at higher temperatures.

Several thousand organic compounds are known to form liquid crystals [19]. In general, liquid crystals have rod-like, fairly rigid structures. Although the liquid crystal molecules may have different transition temperatures between the various phases and mesophases, most have a common structure that usually can be represented as shown below:

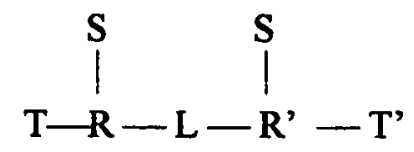

Figure 3. Schematic of the structure of a liquid crystal

Where $R$ and $R$ ' are aromatic ring structures, $L$ is the central linking group, $T$ and $T$ ' are terminal groups, and S and S' are lateral substituents. The properties of the liquid crystal are dependent on the structure. 


\subsubsection{Liquid crystals in gas chromatography}

Due to their ordered nature, liquid crystals have been used as bonded phases in both GC and HPLC. Because the pressures used in GC are much lower than in HPLC, these materials have been used much more in GC, as they can be physically absorbed on the solid support unlike the chemical bonding needed in HPLC.

Liquid crystals have proven to be a valuable and versatile stationary phase for use in gas chromatography particularly for the separation of complex mixtures of isomers of polycyclic aromatic hydrocarbons (PAHs), chiral materials, and other structural isomers with no functional groups [21]. Separation appears to occur mainly due to dissolution into the ordered "slots" of the rigid stationary phase rather than by adsorption [Fig. 4] [22]. According to this theory, planar molecules would be able to fit more easily into these narrow slots and interact strongly with the stationary phase, whereas the non-planar molecules would not penetrate as far into the slots and so would interact less strongly with the stationary phase [22]. Both polymeric and monomeric phases have been made. Polymeric phases exhibit greater selectivity based on molecular shape than monomeric phases. The fact that shape selectivity increases with increased loading for polymeric phases indicates that these phases may be more "extended" or more rigid than monomeric phases.

Besides showing the ability to separate isomers, liquid crystals have several useful properties as stationary phases in GC [22]. GC is usually operated between $50-300^{\circ} \mathrm{C}$, which matches the mesomorphic temperature range of many liquid crystals. Liquid crystals have a high thermal stability leading to long column life [23], and because liquid 
crystals are like viscous liquids, the ability to flow allows them to be easily physically coated on the solid support.

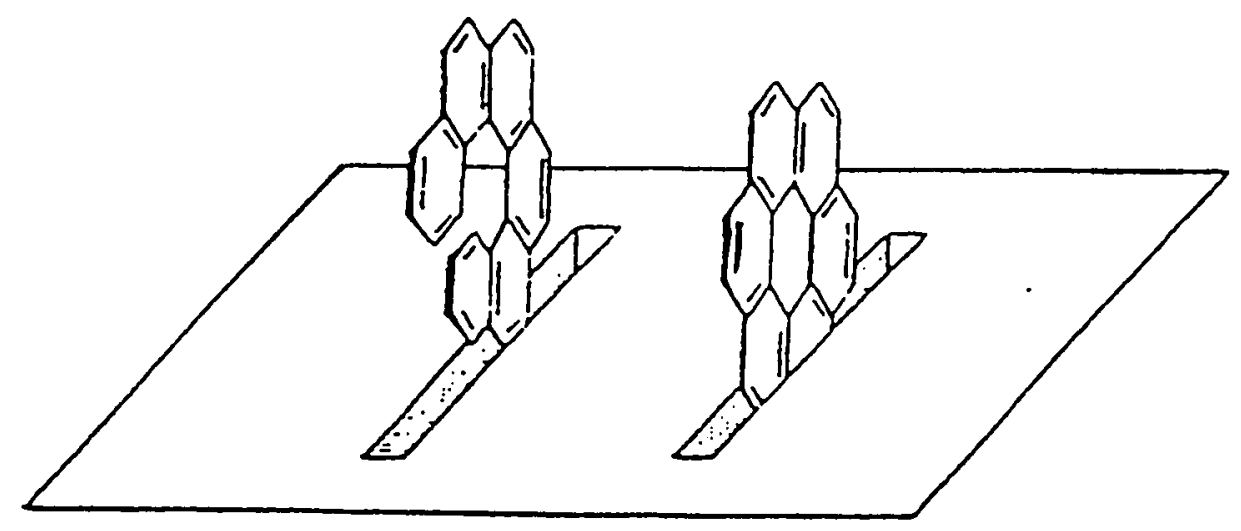

Figure 4. Schematic representation of the "Slot model" for retention of molecule. (Taken from ref. 22.)

\subsubsection{Liquid crystals in HPLC}

In early studies of liquid-crystalline columns in HPLC, the liquid crystal was physically coated on the solid support which resulted in a rapid loss of the stationary phase due to its solubility in the mobile phase or removal by shear forces. A few reports for their use in HPLC have been made $[24,25]$. Therefore, the only practical solution for the production of liquid crystalline stationary phases in HPLC is to adopt a chemical bonding scheme.

Several recent studies have shown that some liquid crystals, or structurally similar 
compounds, when bonded to a polysiloxane backbone, retain or develop liquid crystalline behavior [26]. An example of a successful bonding scheme is shown in Fig. 5. The pathway involves the synthesis of a liquid crystal silane reagent using standard hydrosilylation chemistry. The important step in this reaction scheme is to find a terminal olefin species that is a liquid crystal or can develop liquid-crystalline properties when bonded to a solid matrix.

A directly bonded $\mathrm{Si}-\mathrm{C}$ linkage has been investigated recently by reacting terminal olefins to hydride silica surfaces [17]. A new approach to produce a hydride-modified support that is used in this work involves hydrolysis of triethoxysilane (TES) on silica. A subsequent Si-C bond can be formed directly between the hydride silica and the organic group. The process can be shown in Figure 6. In comparison to the method in Fig. 5 , the approach to produce a hydride-modified support should provide not only a cioser attachment and a denser coverage of organic functionality onto the silica surface and a more hydrolytically stable bonded phase but also greater simplicity of the synthetic procedure $[11,16,17]$.

Bonding a liquid-crystalline compound with a vinyl terminal group (4-methoxyphenyl4-allyloxybenzoate (MPAB) or cholesteryl 10-undeconate to form a stationary phase via a covalent bond has been investigated. The synthesis consists of the preparation of a silica intermediate containing stable, silicon-hydride surface species followed by the catalytic addition of these to organic compounds bearing a terminal vinyl group. Up to this point, the main problem in the bonding process has been a low yield on the silica surface for cholesteryl 10-undecenoate and MPAB (surface coverage is about 0.32 and 1.44 
$\mu \mathrm{mol} / \mathrm{m}^{2}$ ) [17].
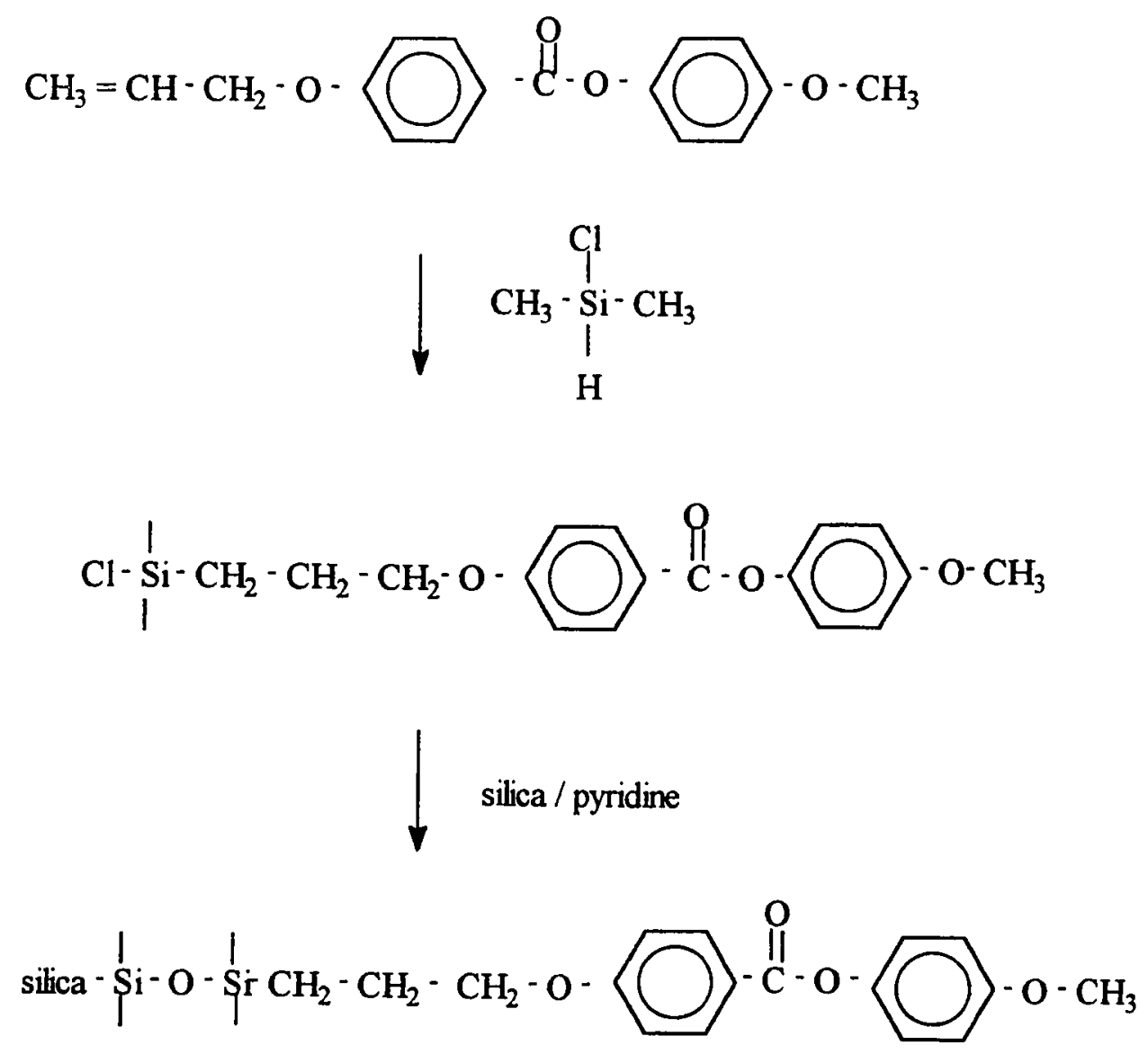

Figure 5. Schematic represent of the bonding of 4-(allyoxy)-4-methoxyphenyl to silica. (Taken from ref 27.) 
$\equiv \mathrm{Si}-\mathrm{OH}+\left(\mathrm{H}_{3} \mathrm{CO}\right)_{3} \mathrm{Si}-\mathrm{H}$

$$
\left.\mathrm{H}_{2} \mathrm{O}\right\rfloor \text { solevent }
$$
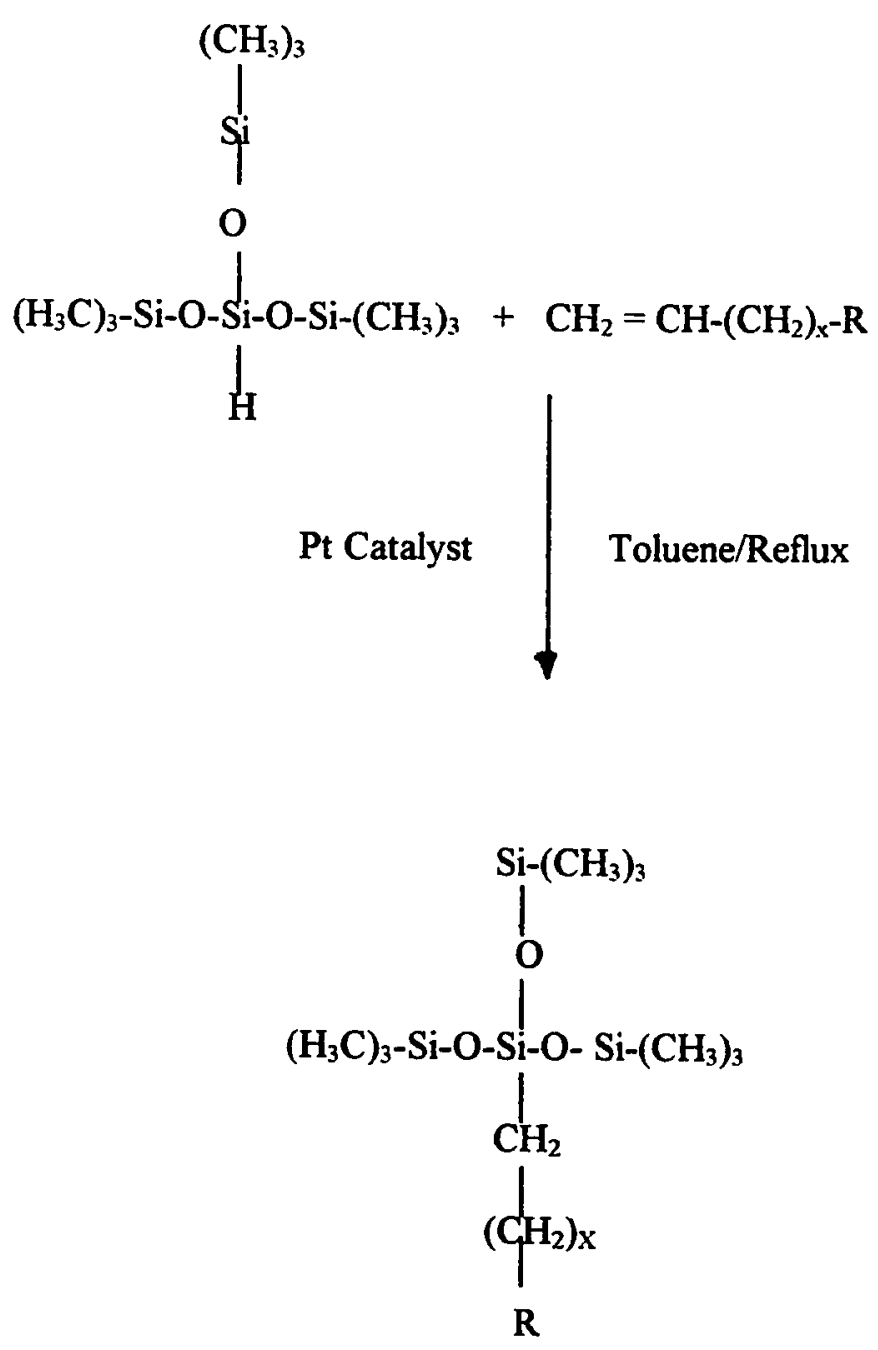

Figure 6. Reaction scheme for the synthesis of liquid crystallint stationary phases. (Taken from ref. 16.) 


\subsection{Characterization techniques}

\subsubsection{Spectroscopic techniques}

Many different techniques have been used to characterize the bonding of various materials to silica supports. Infrared (IR) and nuclear magnetic resonance (NMR) spectroscopy are most often used to provide information on the bonded phase.

DRIFT spectroscopy. Diffuse reflectance infrared Fourier transform (DRIFT) technique is often used to get information about surfaces that can not be obtained from IR analyses done in the transmission mode. DRIFT analyses provide a means of readily identifying the surface species and monitoring chemical changes. Hydride intermediate surfaces consist of a layer of Si-H groups. Since the formation of Si-C linkages results in the removal of $\mathrm{Si}-\mathrm{H}$ species, the presence of a small residual amount of $\mathrm{Si}-\mathrm{H}$ groups can be used to confirm the success of the hydrosilylation reaction to produce a bonded species. When olefins undergo addition, features characteristic of the olefin-containing molecule appear with concomitant depletion of Si-H groups.

NMR spectroscopy. NMR is another useful technique for the study of bonded phases. NMR analyses are often used to provide complementary information to $\mathbb{R}$. Crosspolarization magic angle spinning nuclear magnetic resonance spectroscopy (CP-MAS NMR) is used to improve $\mathrm{S} / \mathrm{N}$ (signal to noise). ${ }^{29} \mathrm{Si}$ CP-MAS NMR is performed on the bonded phases and the support phases, respectively. Due to the formation of Si-C linkages at the expense of $\mathrm{Si}-\mathrm{H}$ species, the change of $\mathrm{Si}-\mathrm{H}$ group resonance can be used 
to indicate the structural changes taking place on the silica surface.

\subsubsection{Elemental analytical technique}

Elemental analysis is performed to determine the percentage loading of the organic moiety on the support surface. It provides a rapid quantitative evaluation of the surface after modification. Surface coverage, $\alpha_{R}$, can be obtained from the measured carbon content of the bonded material and the BET (Brunauer-Emmett-Teller) specific surface area of the hydride silica substrate before bonding [28]

$$
\alpha_{R}\left(\mu \mathrm{mol} / \mathrm{m}^{2}\right)=\frac{10^{6} \mathrm{P}_{\mathrm{c}}}{\left(10^{2} \mathrm{M}_{\mathrm{c}} \mathrm{n}_{\mathrm{c}}-\mathrm{P}_{\mathrm{c}} \mathrm{M}_{\mathrm{R}}\right) \mathrm{S}}
$$

where, assuming a monolayer of organic groups should form on a the hydride silica surface, $\mathbf{P}_{c}$ is the corrected carbon percentage (after subtracting carbon present in the native silica), $M_{c}$ is the atomic weight of carbon, $n_{c}$ is the number of carbon atoms in the bonded organic group (\#C atoms in cholesteryl 10-undecenoate and MPAB), $S$ is the BET specific surface area $\left(\mathrm{m}^{2} / \mathrm{g}\right)$ of the native silica, and $M_{R}$ is the molecular weight of organic species (in this case, the cholesteryl 10-undeconate or MPAB). Because there is no hydrogen lost in this addition reaction, there is no need to subtract the atomic weight of hydrogen from the molecular weight of the bonded molecule. 


\subsubsection{Thermal technique}

The thermal technique used to provide information in the qualitative study of solid support surfaces and bonded phases is differential scanning calorimetry (DSC). The thermal transitions are used to characterize the bonded phases. The behavior of olefins and related materials in the presence of nitrogen at temperatures associates with the phase change, such as the melting point, which is one of the characteristics of the thermal transitions. In an oxygen atmosphere, the oxidative degradation of compounds should be used to characterize the bonded phases. In the case of silane, the species is oxidized into silanol groups:

$\equiv \mathrm{Si}-\mathrm{H}+1 / 2 \mathrm{O}_{2} \rightarrow \equiv \mathrm{Si}-\mathrm{OH}$

Oxygen chemisorption on reduced silica can be characterized by an exothermic peak. In some cases, the transition may not be a simple single step process, especially within the bonded phases [29]. In this case, the structural characteristic of the bonded phase should be reflected by the exothermic peak.

\subsection{Aims of this work}

The general purpose of this work was to develop a liquid-crystalline stationary phase via the hydrosilation procedure given in Figure 6 and to maximize the surface coverage. Two different possible liquid crystalline compounds containing terminal olefins are cholesteryl 10-undecenoate and MPAB. The structure of two compounds is shown in 
Figure 7.

Several factors were investigated to optimize these syntheses. These factors directly affect the bonding reaction. They include the type of catalyst, reaction time, ratio of olefin to silica and catalyst to silica, and reaction temperature. It is expected that under an optimal reaction condition, the new bonded phase will possess a high surface coverage which will give a better chromatographic performance when used as the stationary phase in HPLC.

Several techniques have been used to characterize these stationary phases such as, DRIFT, ${ }^{29} \mathrm{Si}$ CP-MAS NMR, differential scanning calorimetry (DSC), and elemental analysis. These methods have shown that the bonding was successful and gave a surface coverage of about $1.40 \mu \mathrm{mol} / \mathrm{m}^{2}$ for cholesteryl 10 -undecenoate bonded to silica and a $1.83 \mu \mathrm{mol} / \mathrm{m}^{2}$ for MPAB bonded to silica.

Initial studies of the chromatographic behavior of the cholesteryl 10-undecenoate bonded to silica show promise. Separations of PAH's with this bonded material have been accomplished under reverse-phase HPLC conditions. 
A. 4-Methoxyphenyl 4-allyloxy benzoate

$\mathrm{CH}_{2}=\mathrm{CH}-\mathrm{CH}_{2}-\mathrm{O}-\bigcirc \stackrel{\mathrm{O}}{\mathrm{II}}-\mathrm{O}-\bigcirc-\mathrm{O}-\mathrm{CH}_{3}$

B.) Cholesteryl 10-undecenoate

$\mathrm{CH}_{2}=\mathrm{CH}-\mathrm{CH}_{2}-\left(\mathrm{CH}_{2}\right)_{6}-\mathrm{CH}_{2}-\mathrm{C}-\mathrm{O}$

Figure 7. Schematic of the structure of liquid crystals in this work. 


\section{EXPERIMENTAL}

\subsection{Materials}

Synthetic section. All chemicals used in the synthetic procedures were of analyticalreagent grade. Toluene was dried by refluxing with calcium dichloride ( 8 mesh) for 24 hours and distilled before use. Cholesteryl 10-undecenoate was used as purchased from Sigma Chemical Co. and 4-methoxyphenyl-4-allyloxybenzoate was prepared by a method described by Apfel et al [5]. Vydac 101TP (Lot \# 900201) with a $6.583 \mu \mathrm{m}$ mean particle size, $380 \AA$ mean pore size, and $106.5 \mathrm{~m}^{2} / \mathrm{g}$ surface area and Vydac-HS $101 \mathrm{H}$ (Lot \# 920714) with a $7.6 \mu \mathrm{m}$ mean particle size, $0.54 \mathrm{cc} / \mathrm{g}$ mean pore volume, and $280.4 \mathrm{~m}^{2} / \mathrm{g}$ surface area was used as the silica support. The hydride silica was made according to the procedure described by Sandoval [11] and dried at $120^{\circ} \mathrm{C}$ in a vacuum oven overnight prior to use. Stock catalyst solution of $3.57 \times 10^{-3} \mathrm{M}$ chlorotris(triphenylphosphine)rhodium (Wilkinson's catalyst) and $1.9 \times 10^{-3} \mathrm{M}$ 1,2-Bis(diphenylphosphino)ethane nickel (II) chloride) solutions in $10 \mathrm{~mL}$ benzene were made.

Characterization section. Cyclohexanone-2,4-dinitrophenylhydrazone was used as the calibration standard and 7-(2,3-dihydroxyprophl)theophylline was used as the test standard in elemental analysis. IR-quality potassium bromide (Harshaw/Filtrol Partnership) powder was ground by mortar and pestle for $3 \mathrm{~min}$. and was dried at least 24 hours for the FT-IR spectra.

Chromatographic section. Solvents in the HPLC experiments were of chromatographic grade and filtered through a 0.2-0.4 $\mu \mathrm{m}$ filter. Water for chromatographic 
experiments was run through a Millipore apparatus. The column-selectivity-test mixture was used as received from the National Institute of Standards and Technology. The void volume was measured by means of a potassium nitrate peak.

\subsection{Instrumentation}

Differential scanning calorimetry(DSC). DSC measurements were carried out with a Perkin-Elmer Model DSC-7 instrument using uncovered platinum pans. They were performed in nitrogen at $50-200^{\circ} \mathrm{C}$ or in air at temperatures ranging from $50-600^{\circ} \mathrm{C}$. The sample was run against empty pan blanks.

FTIR spectrometry. The Diffuse-reflectance, infrared, Fourier-transform (DRIFT) spectra were obtained on a Perkin-Elmer Model 1800 FT-IR spectrometer equipped with a deuterated triglycine sulfate (DTGS) detector in the $4000-450 \mathrm{~cm}^{-1}$ in the single-beam mode. The background sample was pure $\mathrm{KBr}$ that was ground by mortar and pestle and then dried in an oven at $120^{\circ} \mathrm{C}$ overnight before use. The $\mathrm{KBr}$ was mixed with an equal amount (1:1 mixture by weight) of sample.

NMR. Solid state NMR spectra were taken on a Bruker ( Billerica, MA, USA) MSL 300 spectrometer in a double bearing $\mathrm{ZrO}_{2}$ rotor. The cross-polarization time was 5 $\mathrm{ms}$ and a pulse repetition rate of $5 \mathrm{~s}$ with an magic angle spinning rate of $5 \mathrm{KHz}$.

Elemental analysis. Carbon analysis on bonded silica was done with a Perkin-Elmer model $240 \mathrm{C}$ elemental analyzer equipped with a Perkin-Elmer model 56 recorder by a conventional combustion method. The compound cyclohexanone-2,4-dinitrophenylhydrazone was used as the standard for calibration 7-(2,3-dihydroxypropyl)theophylline was 
used to characterize the instrumental response.

HPLC. Separation measurements were made with Hewlett Packard model 1050 liquid chromatograph system equipped with a UV detector (254 and $210 \mathrm{~nm}$ ). The column material was packed into a $150 \times 4.6 \mathrm{~mm}$ stainless steel column using standard pneumatic amplification techniques with methanol as the driving solvent. The sample size was 5-10 $\mu \mathrm{L}$. All mobile phases were prepared by using standard volumetric glassware and were degassed before use with helium for $10 \mathrm{~min}$. The void volume was measured by means of a potassium nitrate peak.

\subsection{Synthesis of bonding phases}

All glassware for moisture-sensitive synthetic work was dried at $110^{\circ} \mathrm{C}$ for 24 hours prior to use.

\subsubsection{Synthesis of cholesteryl 10-undecenoate bonded to hydrided silica}

A $7.5 \mathrm{~mL}$ portion of distilled, dry toluene was transferred to a $25 \mathrm{~mL}, 3$-necked, round-bottom flask equipped with a $25 \mathrm{~cm}$ condenser, a thermometer, a glass stopper, a 0.5 " magnetic stir bar and a $25 \mathrm{~mL}$ heating mantle outside. $0.836 \mathrm{~g}$ (1.512 mmols) sample of cholesteryl 10-undcenoate was then added to the reaction flask while stirring. After a minute, $0.4 \mathrm{~mL}$ of $1.76 \mathrm{mM}$ ( about a $4.7 \times 10^{-4}$ catalyst : olefin ratio) chlorotris(triphenylphosphine) rhodium ( Wilkinson's catalyst) was added. The mixture was heated and maintained at $100 \pm 2{ }^{\circ} \mathrm{C}$ for about one hour, and then the hydride silica was added to the reaction mixture slowly by rotating a straight glass tube containing the hydride silica. 
Next that the flask was flushed with $\mathrm{N}_{2}$. The reaction was allowed to proceed for 96 hours. The product was centrifuged and washed consecutively while magnetically stirring with four $5 \mathrm{~mL}$ portions of dry toluene followed by similar washings with two $5 \mathrm{~mL}$ portions of methylene chloride and with two $5 \mathrm{~mL}$ portions of ether. The final product was dried at room temperature under vacuum for at least 24 hours.

\subsubsection{Synthesis of MPAB bonded to hydride silica}

A $7.5 \mathrm{~mL}$ portion of distilled, dry toluene was transferred to a $25 \mathrm{~mL}, 3$-necked round-bottom flask equipped with a $25 \mathrm{~cm}$ condenser, a thermometer, a glass stopper, a 0.5 " magnetic stir bar and a $25 \mathrm{~mL}$ heating mantle outside. A $0.215 \mathrm{~g}(0.756 \mathrm{mmols})$ sample of 4-methoxyp-henyl-4-allyloxybenzoate (MPAB) was then added to the reaction flask while stirring. After a minute, $0.2 \mathrm{~mL}$ of $1.76 \mathrm{mM}$ ( about a $4.7 \times 10^{-4}$ catalyst : olefin ratio) chlorotris (triphenylphosphine)rhodium was added. The mixture was heated to and maintained at $100 \pm 2{ }^{\circ} \mathrm{C}$ for about one hour, and then the hydride silica was added to the reaction mixture slowly by rotating a straight glass tube containing the hydride silica. Next that the flask was flushed with $\mathrm{N}_{2}$. The reaction was allowed to proceed for 96 hours. The product was centrifuged and washed consecutively while magnetically stirring 4 times with $5 \mathrm{~mL}$ of dry toluene, 2 times with $5 \mathrm{~mL}$ of methylene chloride, and 2 times with $5 \mathrm{~mL}$ of ether. The final product was dried at room temperature under vacuum for at least 24 hours. 


\subsection{Stability test}

The stability test was performed on cholesteryl 10-undeconate bonded on silica prepared using Vydac 101TP as the support. After the stability test, the thermal transition of the liquid crystal was obtained with DSC, the composition of material was monitored by DRIFT, and measurement of carbon content (percent by weight) was determined by elemental analysis.

\subsection{1 $\mathrm{pH}$ stability testing of bonded material}

Buffer solutions were prepared at both $\mathrm{pH} 2.87$ and 7.96. A $17.5 \mathrm{~mL}$ of $0.2 \mathrm{M}$ $\mathrm{NaOH}$ was added to $100 \mathrm{~mL}$ of stock solution $\left(0.04 \mathrm{M}\right.$ acetic, $0.04 \mathrm{M} \mathrm{H} \mathrm{HOO}_{4}$, and $0.04 \mathrm{M}$ boric acid) to obtain $\mathrm{pH}=2.87$. A $60.0 \mathrm{~mL}$ of $0.2 \mathrm{M} \mathrm{NaOH}$ was added to $100 \mathrm{~mL}$ stock solution to get $\mathrm{pH}=7.96 .0 .3 \mathrm{~g}$ of the bonded material was added to a $10 \mathrm{~mL}$ buffer solution described above for the cholesteryl 10-undecenoate test at $\mathrm{pH}=2.87$ and $\mathrm{pH}=7.96$. The sample was magnetically stirred for 24 hours at room temperature. After this period, a $2 \mathrm{~mL}$ aliquot was taken and the liquid was removed by centrifugation for checking the surface coverage. The procedure was repeated over a total time of about 5 days. The bonded material was washed 5 times with water and dried at $110^{\circ} \mathrm{C}$ under vacuum for several hours.

\subsubsection{Solvent stability testing of bonded material}

Approximately $3.5 \mathrm{~g}$ of bonded phase material was placed in a $25 \mathrm{~mL}$ flask containing $2 \mathrm{~mL}$ of methanol and magnetically stirred for $10 \mathrm{~min}$. Then, $20 \mathrm{~mL}$ of acetonitrile was 
added and continuously stirred at room temperature for 24 hours. A $2 \mathrm{~mL}$ aliquot of the solution was taken and was washed consecutively with $2.5 \mathrm{~mL}$ toluene, methylene chloride, and ether. The solid was dried at room temperature under vacuum for 24 hours.

\subsubsection{Water stability testing of bonded material}

$0.3 \mathrm{~g}$ of bonded phase material was added to $10 \mathrm{~mL}$ of water (HPLC grade) with magnetic stirring in order to ensure good contact between the liquid and the solid. $2 \mathrm{~mL}$ of the suspension was taken every 24 hours and the ratio of solid to liquid was kept constant. The bonded material was centrifuged to remove liquid. The solid was dried at $110^{\circ} \mathrm{C}$ under vacuum for several hours. 


\section{RESULTS AND DISCUSSION}

The main purpose in this study was to examine the possibility of bonding liquid crystals via a hydride intermediate to a silica support and to maximize the surface coverage by optimizing the synthetic conditions. Product formation can be monitored by thermal, spectroscopic, and elemental analysis.

\subsection{Spectroscopic evaluation}

Many approaches have been used to characterize the feasibility of bonding organic moieties to silica supports bearing surface $\mathrm{Si}-\mathrm{H}$ groups. Two of the easiest and most convenient methods are DRIFT and CP-MAS NMR spectroscopy. The formation of Si-C linkages on the silica surface is confirmed by the changes in spectral bands associated with the $\mathrm{Si}-\mathrm{H}$ species as well as $\mathrm{C}-\mathrm{H}, \mathrm{C}=\mathrm{O}$, and $\mathrm{C}=\mathrm{C}$ groups within the liquid crystal before and after bonding. Information on the success of the bonding can be qualitatively obtained. The structures of the liquid crystals and the chemical modification of silica surfaces can be easily monitored by these techniques.

\subsubsection{DRIFT characterization}

\subsubsection{Silica hydride}

The silanols on the unmodified silica reacts with TES to form the silica hydride. The Si-H group on the silica hydride is identified by a strong stretching band in the DRIFT spectrum. A sharp peak represents the characteristic Si-H stretch at $2260 \mathrm{~cm}^{-1}$, along with 
a relatively weak bending band between $760-910 \mathrm{~cm}^{-1}$ as shown in curve A of Fig. 8 .

Another band at $3750 \mathrm{~cm}^{-1}$ is due to $\mathrm{O}-\mathrm{H}$ stretching of isolated silanols. The presence of chemisorbed carbon is observable in the form of very weak $\mathrm{C}-\mathrm{H}$ stretching peaks in the $2900-3000 \mathrm{~cm}^{-1}$ region. These peaks are the principle bands of silica hydride used for confirming structural changes.

\subsubsection{Cholesteryl 10-undecenoate and Cholesteryl 10-undecenoate bonded phase}

The DRIFT spectrum of unbounded cholesteryl 10-undecenoate is shown in Figure 9. The peak at $3080 \mathrm{~cm}^{-1}$ results from the $\mathrm{C}-\mathrm{H}$ stretch of the terminal alkene. The peaks between $3000-2850 \mathrm{~cm}^{-1}$ are indicative aliphatic of $\mathrm{C}-\mathrm{H}$ stretching. The appearance of a strong stretching band at $1731 \mathrm{~cm}^{-1}$ indicates the presence of a $\mathrm{C}=\mathrm{O}$ group. The strong absorption band near $1630 \mathrm{~cm}^{-1}$ results from the $\mathrm{C}=\mathrm{C}$ double bond stretch. A peak at $1468 \mathrm{~cm}^{-1}$ comes from a C-H bending frequency. The peak at $1170 \mathrm{~cm}^{-1}$ represents the C-O ester stretch.

After cholesteryl 10-undecenoate is bonded to silica, (curve B in Figure 8) clearly a significant chemical change can be seen with the appearance of $\mathrm{C}-\mathrm{H}$ stretching bands of in the $3000-2800 \mathrm{~cm}^{-1}$ region and an absorption band at $1710 \mathrm{~cm}^{-1}$ that is indicative of a carbonyl. Also seen is a substantial decline of the Si-H stretching band at $2260 \mathrm{~cm}^{-1}$ and the complete disappearance of both the olefin $\mathrm{C}-\mathrm{H}$ stretch at $3080 \mathrm{~cm}^{-1}$ and the $\mathrm{C}=\mathrm{C}$ band at $1637 \mathrm{~cm}^{-1}$. All of these changes indicate that the bonding process was successfully completed. 


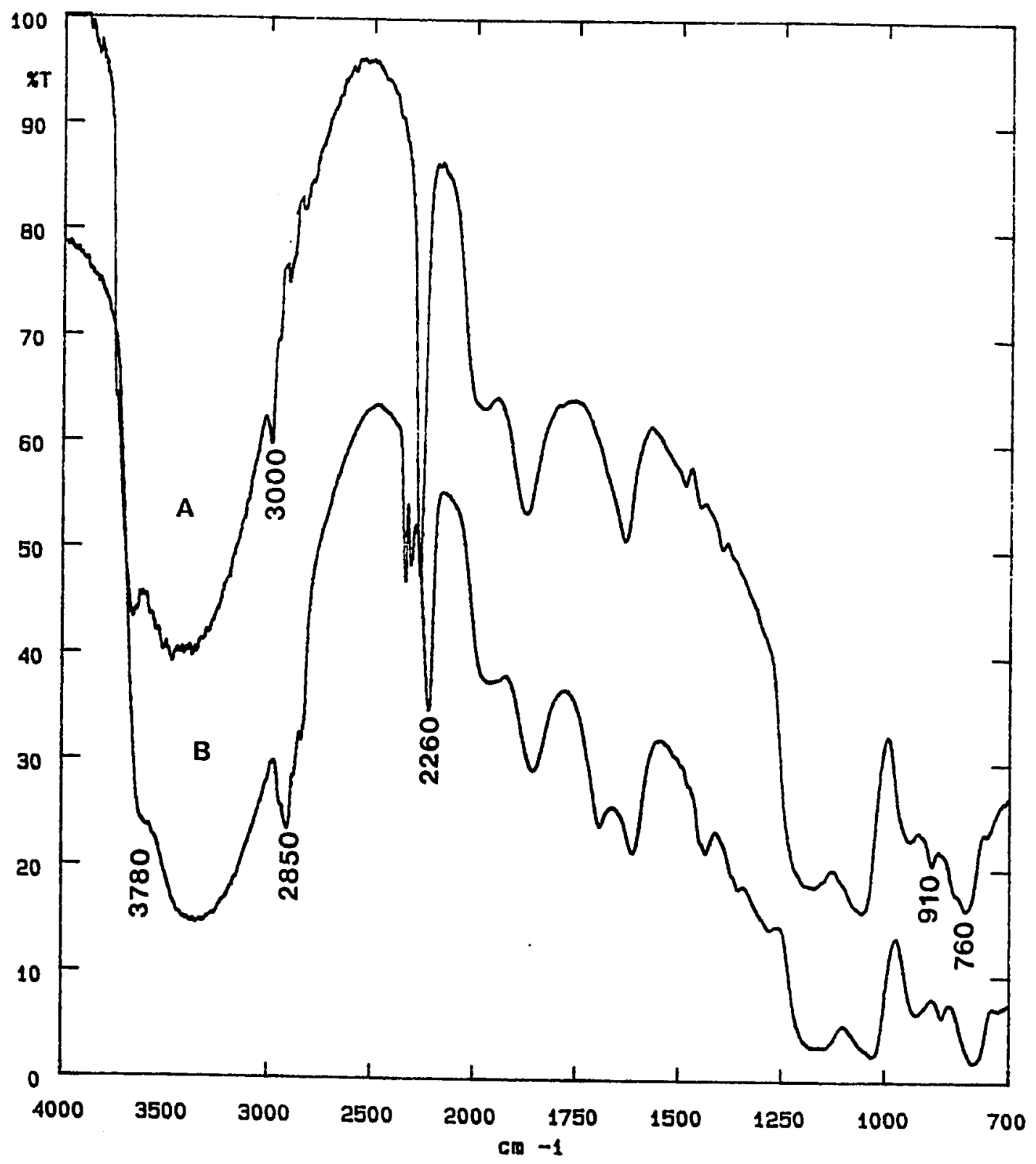

Figure 8. Partial DRIFT spectrum of cholesteryl 10-undecenoate bonded to hydride silica: (A) hydride silica and (B) bonded phase. 


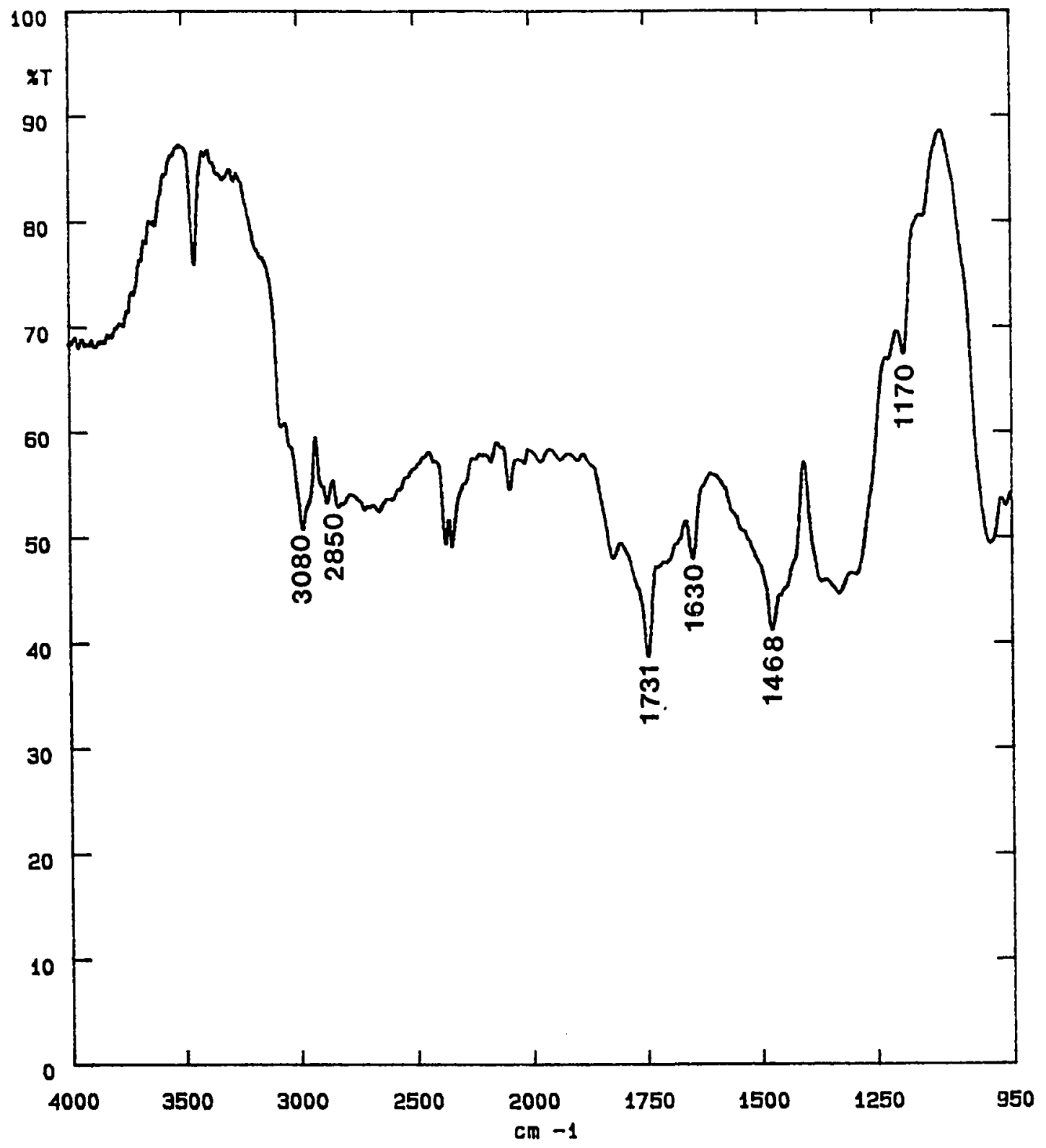

Figure 9. DRIFT spectrum of cholesteryl 10-undecenoate. 


\subsubsection{MPAB and MPAB bonded phase}

The DRIFT spectrum of MPAB is shown in curve A of Figure 10. The peak at 3082 $\mathrm{cm}^{-1}$ represents the $\mathrm{C}-\mathrm{H}$ stretch frequency of the terminal double bond, the peaks between $3050-3000 \mathrm{~cm}^{-1}$ represent aromatic C-H stretching, those between $3000-2850 \mathrm{~cm}^{-1}$ are for aliphatic $\mathrm{C}-\mathrm{H}$ stretch, the peak at $1738 \mathrm{~cm}^{-1}$ represents the $\mathrm{C}=\mathrm{O}$ stretch, that at $1510 \mathrm{~cm}-{ }^{-1}$ represents the $\mathrm{C}-\mathrm{O}$ ester stretch, the one at $1600 \mathrm{~cm}^{-1}$ represents the $\mathrm{C}=\mathrm{C}$ double stretch, and the peak at $1173 \mathrm{~cm}^{-1}$ represents aromatic $\mathrm{C}-\mathrm{H}$ bending.

The DRIFT spectrum of MPAB bonded to silica is shown in Figure 11. Significant aromatic and aliphatic C-H stretching are observed between $3050-2850 \mathrm{~cm}^{-1}$. A decrease in the $\mathrm{Si}-\mathrm{H}$ band intensity at $2260 \mathrm{~cm}^{-1}$, the peak appearing at 1738 for the $\mathrm{C}=\mathrm{O}$ band, a peak at $1510 \mathrm{~cm}^{-1}$ for the $\mathrm{C}-\mathrm{O}$ band, and the one at $1173 \mathrm{~cm}^{-1}$ for $\mathrm{C}-\mathrm{H}$ band, and the complete disappearance of the $\mathrm{C}=\mathrm{C}$ band at $1600 \mathrm{~cm}^{-1}$ indicate successful bonding to silica.

\subsubsection{NMR characterization}

CP MAS NMR are used to get further information into the structure of the silica hydride and the bonded phases. Figure 12 (curve A) shows the ${ }^{29} \mathrm{Si}$ CP-MAS NMR spectrum of the hydride silica. Peaks in the spectrum due to siloxanes $\mathrm{Si}^{*}(\mathrm{OSi} \equiv)_{4}$ at 109.6 ppm, surface single silanols $\mathrm{HO}-\mathrm{Si}^{*}(\mathrm{OSi} \equiv)_{3}$ at $-100.6 \mathrm{ppm}$, and surface silica hydride $\mathrm{H}-\mathrm{Si}^{*}(\mathrm{OSi})_{3}$ at $-83.7 \mathrm{ppm}$ can be identified. The resonance at about $-74.8 \mathrm{ppm}$ in the spectrum is due to the $\mathrm{H}-\mathrm{Si}^{*}(\mathrm{OH})(\mathrm{OSi}=)_{2}$ group. The ${ }^{29} \mathrm{Si} \mathrm{CP}-\mathrm{MAS}$ NMR spectra of cholesteryl 10-undecenoate and MPAB bonded to silica hydride are shown in curve B 


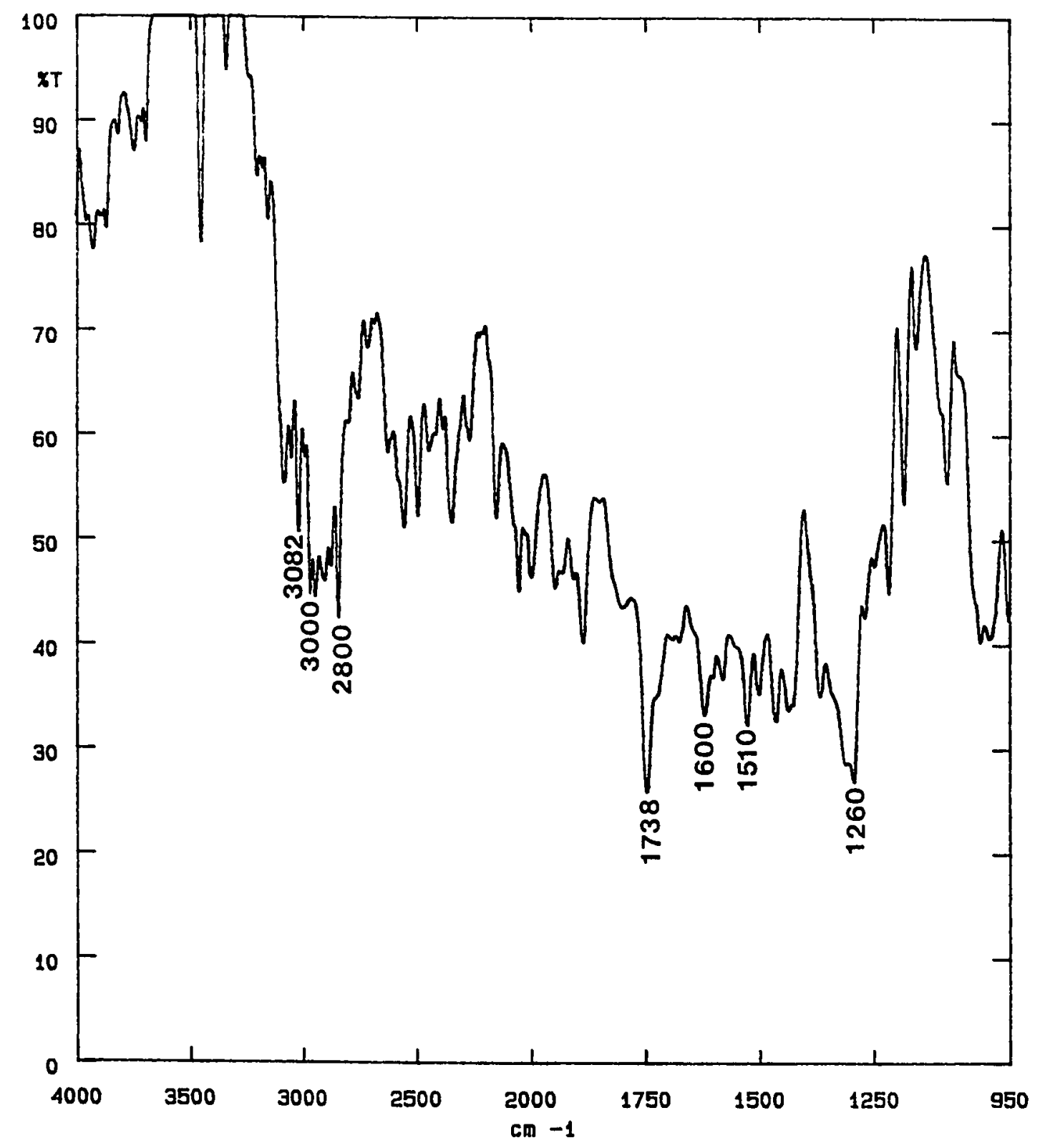

Figure 10. DRIFT spectrum of 4-methoxyphenyl 4-allyloxybenzoate. 


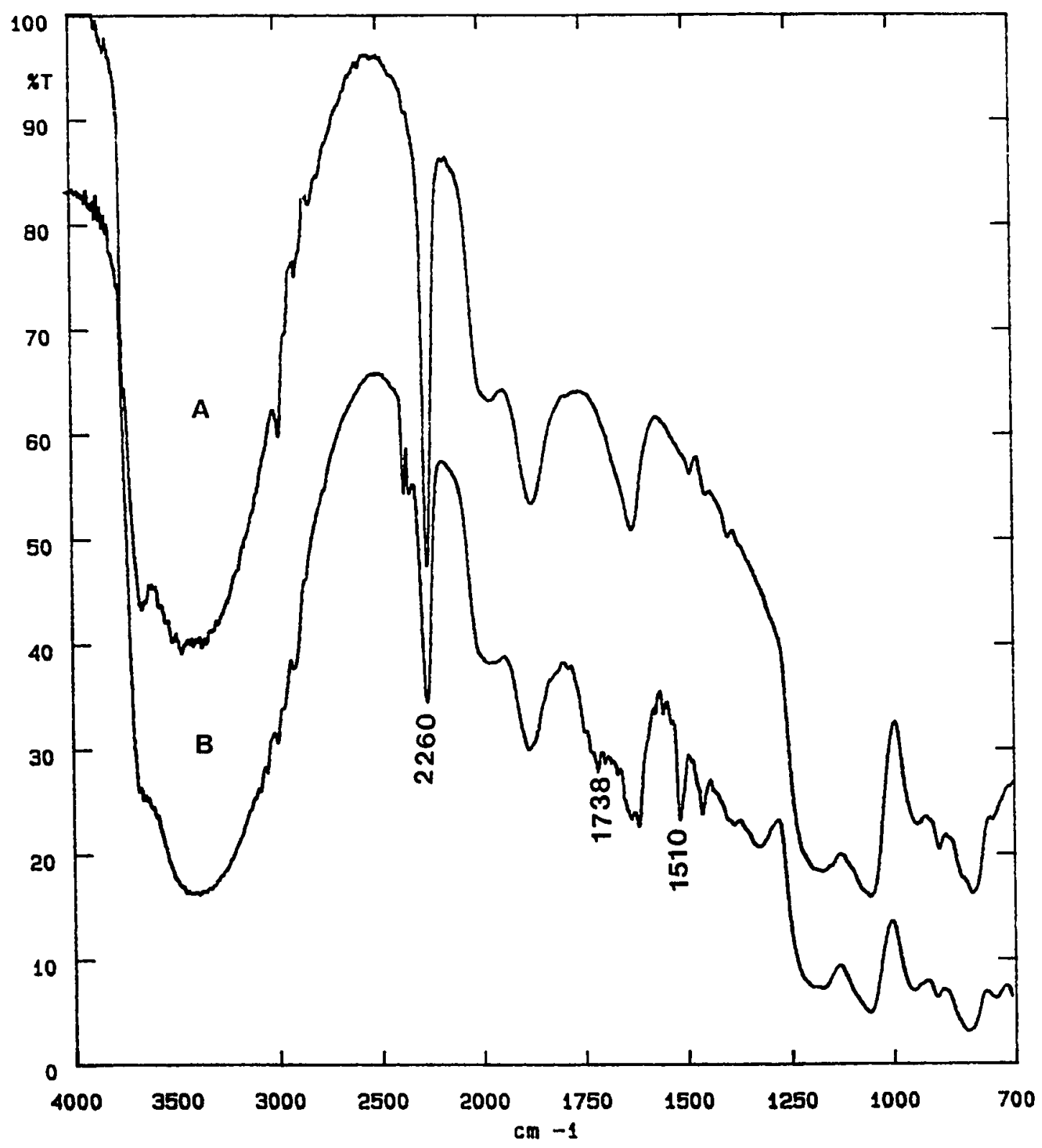

Figure 11. Partial DRIFT spectra of 4-methoxyphenyl 4-allyloxybenzoate bonded to silica: (A) hydride silica and (B) bonded phase. 


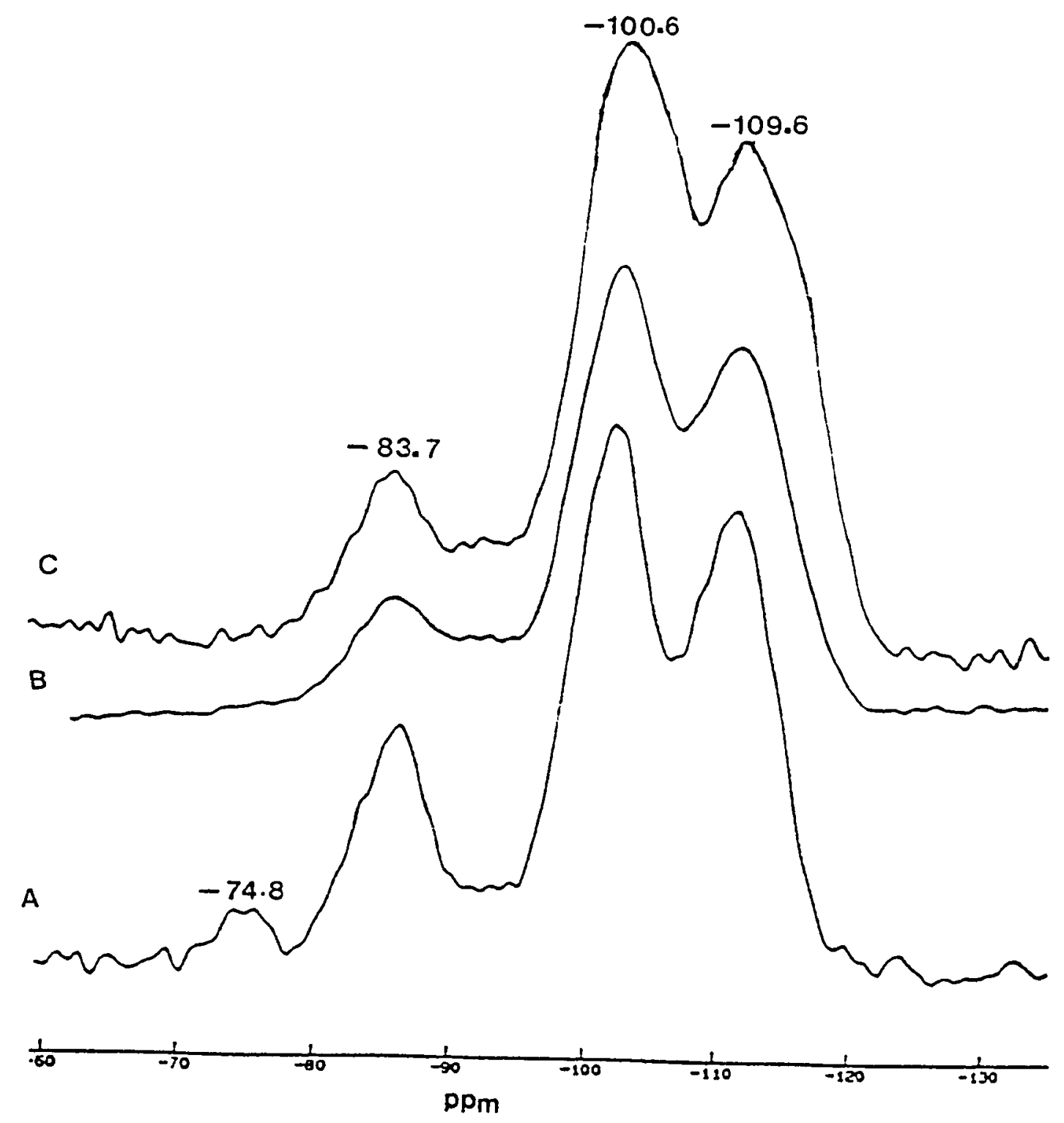

Figure 12. ${ }^{29}$ Si CP-MAS NMR spectra of olefins bonded to silica: (A) hydride silica; (B) 4-methoxyphenyl 4-allyloxybenzoate bonded phase cholesteryl; and (C) 10-undecanoate bonded phase. 
and $C$, respectively. The peaks at -109.6 and $-100.6 \mathrm{ppm}$ do not change. The two peaks at -83.7 and -74.8 ppm have obviously decreased due to the bonding reaction.

\subsection{Surface coverage}

Because the bonded phases are organic in nature and Si-C linkages are formed during the removal of $\mathrm{Si}-\mathrm{H}$ species, the carbon content is used to evaluate the reaction. The weight $\%$ of carbon was obtained from elemental analysis. It is expected that high surface coverage of the organic species will lead to better chromatographic performance. The surface coverage is greatly dependent on the reaction conditions.

\subsubsection{Effect of olefin to silica to catalyst ratio}

In the reaction bonding olefin to silica hydride, transition metals from group VIII are used to catalyzed the reaction. Because the amounts of olefin, silica, and catalyst affect the amount of Si-C linkages, several ratio possibilities, catalyst/silica, catalyst/olefin, and olefin/silica, have been studied. The effects of the various reaction conditions will be reflected by surface coverage of bonded compound.

\subsubsection{Change of catalyst concentration}

It is a well-known fact that the nature and concentration of the catalyst can strongly affect hydrosilation [30,31]. The influence of catalyst concentration was examined under a constant silica amount at $65^{\circ} \mathrm{C}$ for 96 hours. The results are shown in Figure 13. In the case of cholesteryl 10-undecenoate bonded to silica, the surface coverage changes a little 


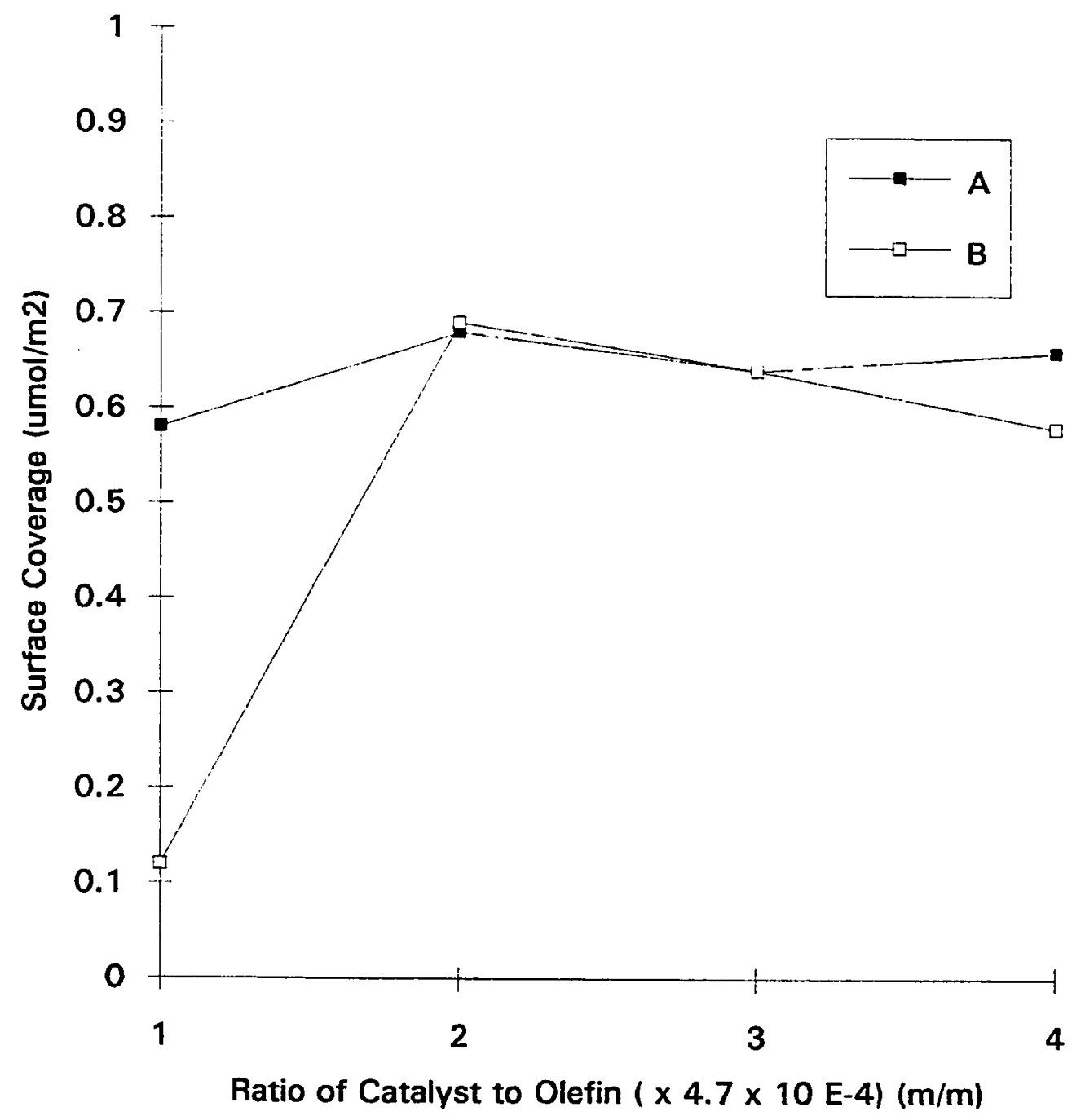

Figure 13. Surface coverage as a function of catalyst concentration in bonded phases of (A) - cholesteryl 10-undecenoate and (B) -- $\square-$ 4-methoxyphenyl 4-allyloxybenzoate. Olefin : silica $=2: 1(\mathrm{w} / \mathrm{w})$; at $65^{\circ} \mathrm{C} ; 96 \mathrm{hr}$. time. 
with the concentration of the catalyst and in the case of MPAB bonded to silica, the surface coverage change is large from $1: 1$ to $1: 2$ ratio. The higher surface coverage for both two olefins bonded to silica can be obtained at the ratio of catalyst to olefin is $2 \mathrm{x}$ $4.7 \times 10^{-4}(\mathrm{~m} / \mathrm{m})$. The fact that surface coverage decreases with the increasing of the catalyst concentration after the $2 \times 4.7 \times 10^{-4}$ ratio of catalyst to olefin may explain that relative large amounts of catalyst induce the possibility to physically block further interaction of organic compounds with silica species. The carbon analysis is shown in Table 1.

\subsubsection{Change of olefin concentration}

The effect of olefin concentration on surface coverage is shown in Table 2 . Under the same reaction conditions, the changes of surface coverage with the olefin content are different. In the case of cholesteryl 10-undecenoate bonded to silica, the surface coverage

at a $2 \times 2.8 \times 10^{-4}$ ratio of the catalyst to silica $(w / w)$ is higher than that at a $1 \times 2.8 \times 10^{-4}$ ratio. In contrast, in the case of MPAB bonded to silica, the surface coverage at a $2 \times 2.8$ $\times 10^{-4}$ ratio of the catalyst to silica $(w / w)$ is lower than that at $1 \times 2.8 \times 10^{-4}$ ratio.

\subsubsection{Effect of reaction time}

To optimize reaction yield, the effects of reaction times were investigated. The reaction solution was sampled every 24 hour period for 120 hours. The bonded species were analyzed for carbon content. The plots of surface coverage as a function of reaction time are shown in Figure 14, in which curve A shows cholesteryl bonded to silica and 
Table 1. Effect of Catalyst Concentration to Surface Coverage for Cholesteryl 10Undecenoate and MPAB Bonded to Silica (At $65^{\circ} \mathrm{C}$, for $96 \mathrm{hr}$ )

\begin{tabular}{|c|c|c|c|c|}
\hline \multirow[t]{2}{*}{$\begin{array}{l}\text { Ratio of catalyst to olefin } \\
\qquad \times 4.7 \times 10^{-4}(\mathrm{~m} / \mathrm{m})\end{array}$} & \multicolumn{2}{|c|}{$\begin{array}{l}\text { Corrected carbon } \\
\qquad \%\end{array}$} & \multicolumn{2}{|c|}{$\begin{array}{c}\text { Surface coverage } \\
\mu \mathrm{mol} / \mathrm{m}^{2}\end{array}$} \\
\hline & I & II & I & II \\
\hline 1 & 3.08 & 0.17 & 0.58 & 0.12 \\
\hline 2 & 3.75 & 1.46 & 0.68 & 0.69 \\
\hline 3 & 2.98 & 1.36 & 0.64 & 0.63 \\
\hline 4 & 3.09 & 1.23 & 0.66 & 0.58 \\
\hline
\end{tabular}

Note: Column I -- from cholesteryl 10-undecenoate bonded to silica.

Column II -- from MPAB bonded to silica.

$\operatorname{Error}( \pm)=0.3-0.5$ 
Table 2. Surface Coverage as a Function of Ratio of Liquid Crystal /Silica for Liquid Crystals Bonded to Hydride Silica (At $65^{\circ} \mathrm{C}, 96 \mathrm{hr}$ )

\begin{tabular}{|c|c|c|c|c|c|}
\hline \multirow[t]{2}{*}{ Liquid crystal } & \multirow[t]{2}{*}{$\begin{array}{l}\text { Ratio of liquid } \\
\text { crystal /silica (w/w) }\end{array}$} & \multicolumn{2}{|c|}{$\begin{array}{l}\text { Corrected Carbon } \\
\text { carbon \% }\end{array}$} & \multicolumn{2}{|c|}{$\begin{array}{l}\text { Surface coverage } \\
\qquad \mu \mathrm{mol} / \mathrm{m}^{2}\end{array}$} \\
\hline & & I & II & I & II \\
\hline \multicolumn{6}{|l|}{ Cholesteryl } \\
\hline 10-undecenoate & 1 & 1.89 & 2.25 & 0.39 & 0.47 \\
\hline \multicolumn{6}{|l|}{ Cholesteryl } \\
\hline 10-undecenoate & 2 & 3.08 & 3.17 & 0.58 & 0.68 \\
\hline MPAB & 1 & 1.77 & 0.52 & 0.83 & 0.22 \\
\hline MPAB & 2 & 0.21 & 1.46 & 0.12 & 0.69 \\
\hline
\end{tabular}

Note: Column I-- Refers to $1 \times 2.8 \times 10^{-4}$ catalyst/silica (w/w).

Column II-- Refers to $2 \times 2.8 \times 10^{-4}$ catalyst/silica (w/w).

$\operatorname{Error}( \pm)=0.3-0.5$ 


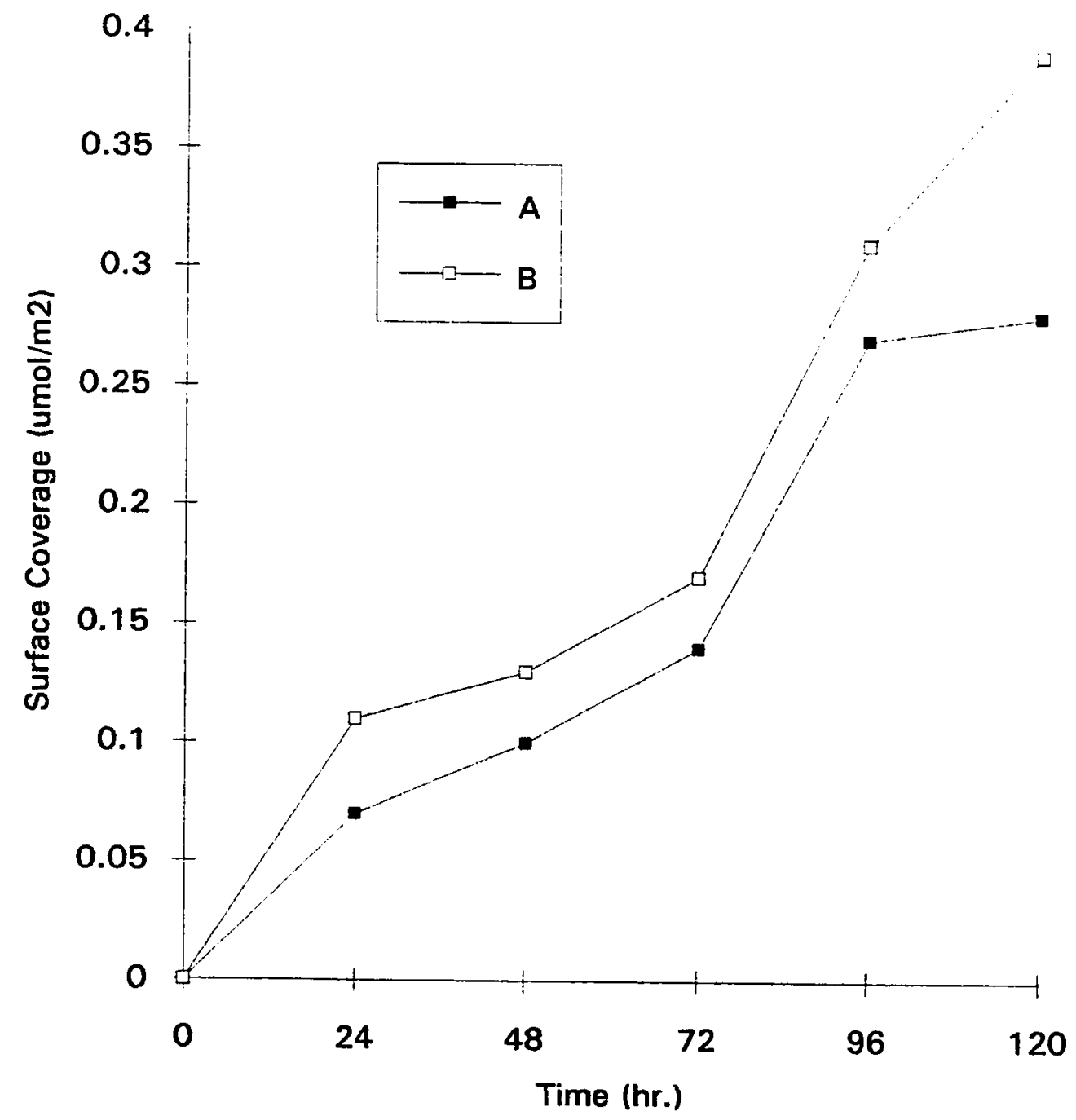

Figure 14. Effect of reaction time on surface coverage in bonded phases of (A) cholesteryl 10-undecenoate and (B) 4-methoxyphenyl 4-allyloxybenzoate; $65{ }^{0} \mathrm{C}$ temperature; ratio of olefins : silica $=1: 1(w / w)$. 
curve $B$ indicates MPAB bonded to silica. During the early stages of the reaction, general increases in surface coverage occur very slowly and a main change of the surface coverage occurs between 72- 96 hours.

\subsubsection{Effect of reaction temperature}

The reaction temperature strongly affects the surface coverage as shown in Figure 15. The use of high reaction temperatures, up to a point, leads to higher surface coverage. When the temperature of the reaction is close to the boiling point of the solvent (toluene $108{ }^{\circ} \mathrm{C}$ ), the surface coverage drops down, which can be understood from the thermal stabilities of the olefin, the product, and the catalyst. The plot suggests that the surface coverage reached a maximum at about $100^{\circ} \mathrm{C}$.

\subsubsection{Effect of catalysts}

Under the same reaction conditions, the nature of the catalyst also affects the surface hydrosilation of liquid crystals based on the difference of catalytic activity. Two different catalytic systems were tested for the hydrosilation of liquid crystals on modified silica. They are chlorotris(triphenylphosphine)rhodium and 1,2 - bis(diphenylphosphino)ethane nickel(II)chloride. Under the same reaction conditions the effect of the catalyst on surface coverage is shown in Table 3. Comparing the results under equivalent amounts of both catalysts, surface coverages for cholesteryl 10 -undeconate on silica are $1.05 \mu \mathrm{mol} / \mathrm{m}^{2}$, when 1,2 - bis(diphenylphosphino)ethane nickel(II)chloride is used as the catalyst, and $1.39 \mu \mathrm{mol} / \mathrm{m}^{2}$, when chlorotris(triphenylphosphine)rhodium was used as the catalyst. In 


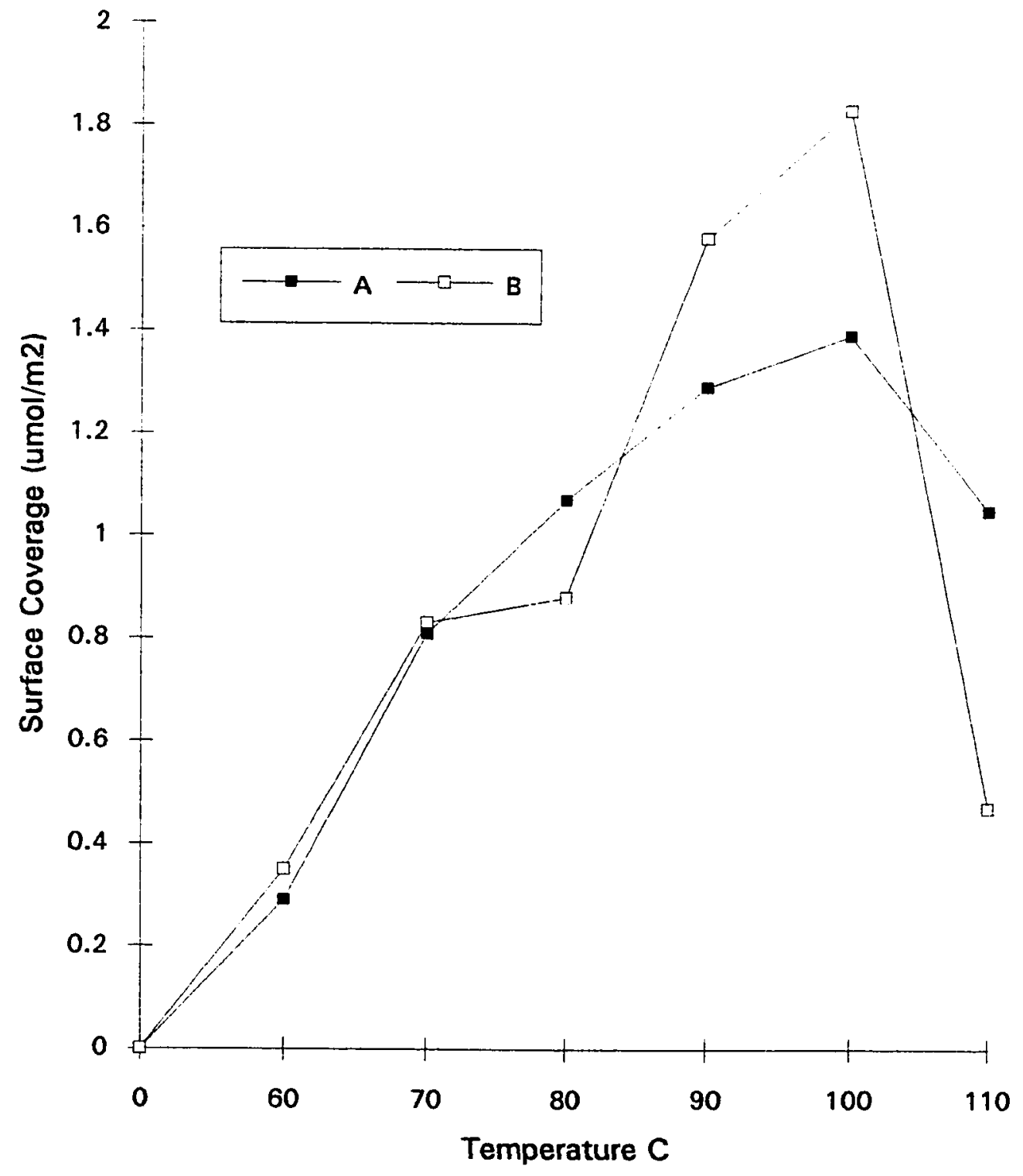

Figure 15. Effect of reaction temperature on surface coverage in bonded phases of (A) cholesteryl 10-undecenoate and (B) 4-methoxyphenyl 4-allyloxybenzoate; olefin : silica = $1: 1(w / w) ; 96$ hours reaction time. 
Table 3. Effect of Catalyst Systems on Surface Coverage for the Hydrosilation of Liquid Crystals on Hydride Silica (At $65^{\circ} \mathrm{C}$, for $96 \mathrm{hr}$ )

\begin{tabular}{|c|c|c|c|}
\hline Liquid Crystals & Catalyst & $\begin{array}{c}\text { Corrected Carbon } \\
\%\end{array}$ & $\begin{array}{c}\text { Surface Coverage } \\
\mu \mathrm{mol} / \mathrm{m}^{2}\end{array}$ \\
\hline \multicolumn{4}{|l|}{ Cholesteryl } \\
\hline 10-undecenoate & $\mathbf{R h}^{*}$ & 6.25 & 1.39 \\
\hline \multicolumn{4}{|l|}{ Cholesteryl } \\
\hline 10-undecenoate & $\mathrm{Ni} * *$ & 4.79 & 1.05 \\
\hline MPAB & $\mathrm{Rh} *$ & 3.76 & 1.83 \\
\hline MPAB & $\mathrm{Ni} * *$ & 4.16 & 2.03 \\
\hline \multicolumn{4}{|c|}{ * -- Chlorotris(triphenylphosphine)rhodium. } \\
\hline \multicolumn{4}{|c|}{ ** - 1,2-Bis(diphenylphosphino)ethane nickel(II) chloride. } \\
\hline \multicolumn{4}{|c|}{ Catalyst : Olefin $=2 \times 4.7 \times 10^{-4}(\mathrm{~m} / \mathrm{m})$ for cholesteryl 10-undecenoate and } \\
\hline
\end{tabular}


contrast, the surface coverage of MPAB on silica when using the nickel chloride complex results in a higher level of surface coverage $\left(2.03 \mu \mathrm{mol} / \mathrm{m}^{2}\right.$ to $\left.1.83 \mu \mathrm{mol} / \mathrm{m}^{2}\right)$ when compared to Rh complex. The plot in Figure 16 shows the DRIFT spectrum of cholesteryl 10-undecenoate modified silica from the two different catalyst systems. The appearance of strong stretching bands in the $3000-2800-\mathrm{cm}^{-1}$ region concomitant with a substantial decline of the $\mathrm{Si}-\mathrm{H}$ stretching band at $2260 \mathrm{~cm}^{-1}$ clearly indicates that there is no noticeable difference in the DRIFT for the two catalysts. Figure 17 shows the same result for MPAB using the two different kinds of catalyst. The main practical difference between the two catalyst complexes is that chlorotris(triphenylphosphine)rhodium is easily dissolvable in toluene when bonding olefins to silica.

\subsubsection{Suggested experiments conditions}

From the experiments described above, the current optimum reaction conditions for silanization include (i) toluene as a solvent; (ii) a 2:1:2 ratio of cholesteryl to silica to catalyst and a 1:1:1 ratio of MPAB to silica to catalyst; (iii) a $1.76 \mathrm{mM}$ chlorotris (triphenylphosphine)rhodium catalyst; (iv) a reaction time of 96 hours; and (v) a reaction temperature of $100 \pm 2{ }^{\circ} \mathrm{C}$.

\subsection{Thermal analysis}

The DSC technique can produce valuable information about the thermal behavior of cholesteryl 10-undecenoate, MPAB, and other bonded materials. Figures 18 and 19 illustrate DSC curves for cholesteryl 10-undecenoate and MPAB in the presence of an 


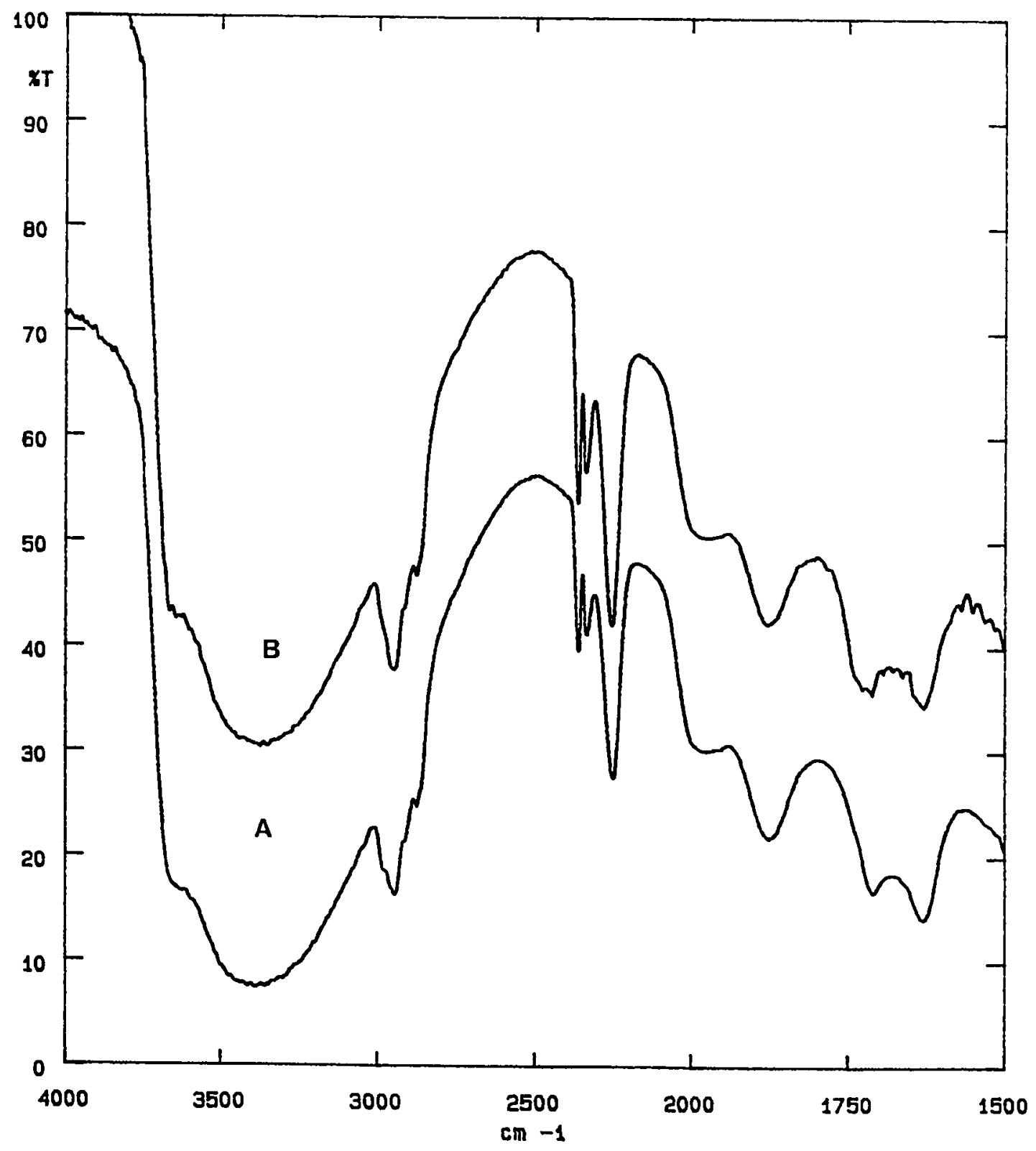

Figure 16. DRIFT spectra of cholesteryl 10-undecenoate bonded to hydride silica in two different catalyst systems: (A) in Rh catalyst system and (B) in Ni catalyst system. 


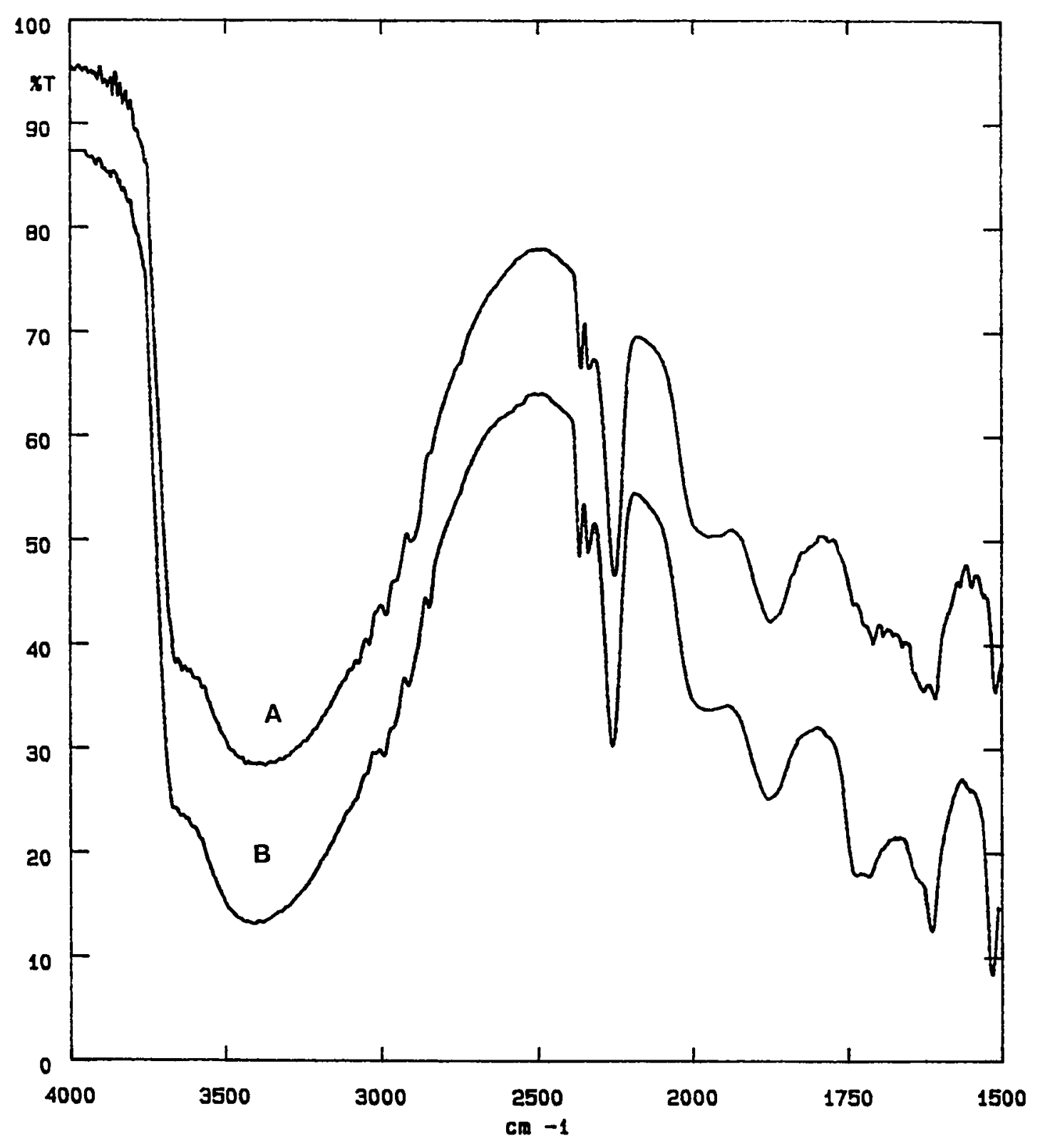

Figure 17. DRIFT spectra of 4-methoxyphenyl 4-allyloxybenzoate bonded to hydride silica in (A) Rh catalyst system and (B) Ni catalyst system. 


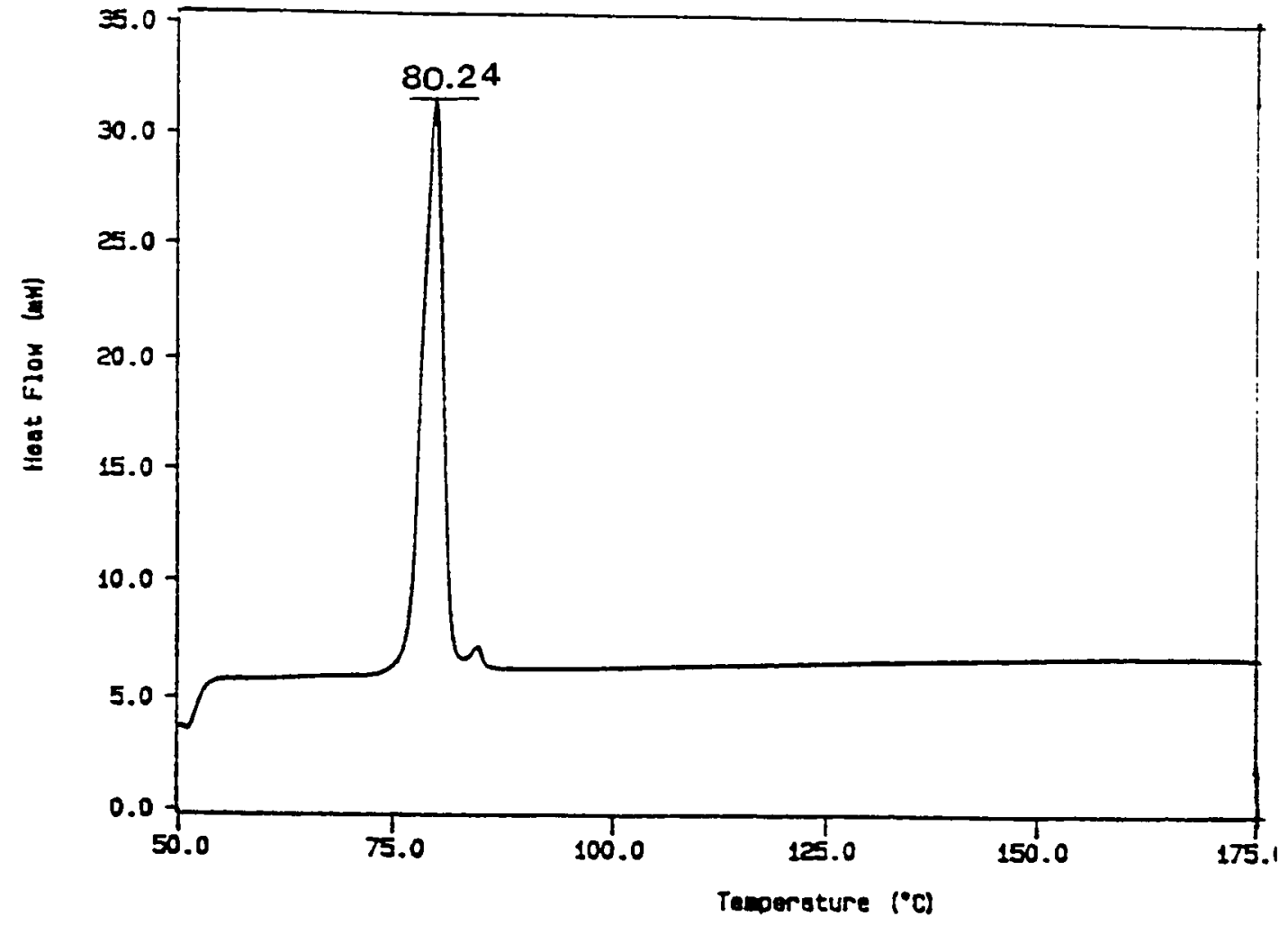

Figure 18. DSC thermogram of cholesteryl 10-undecenoate in $\mathrm{N}_{2}$ 


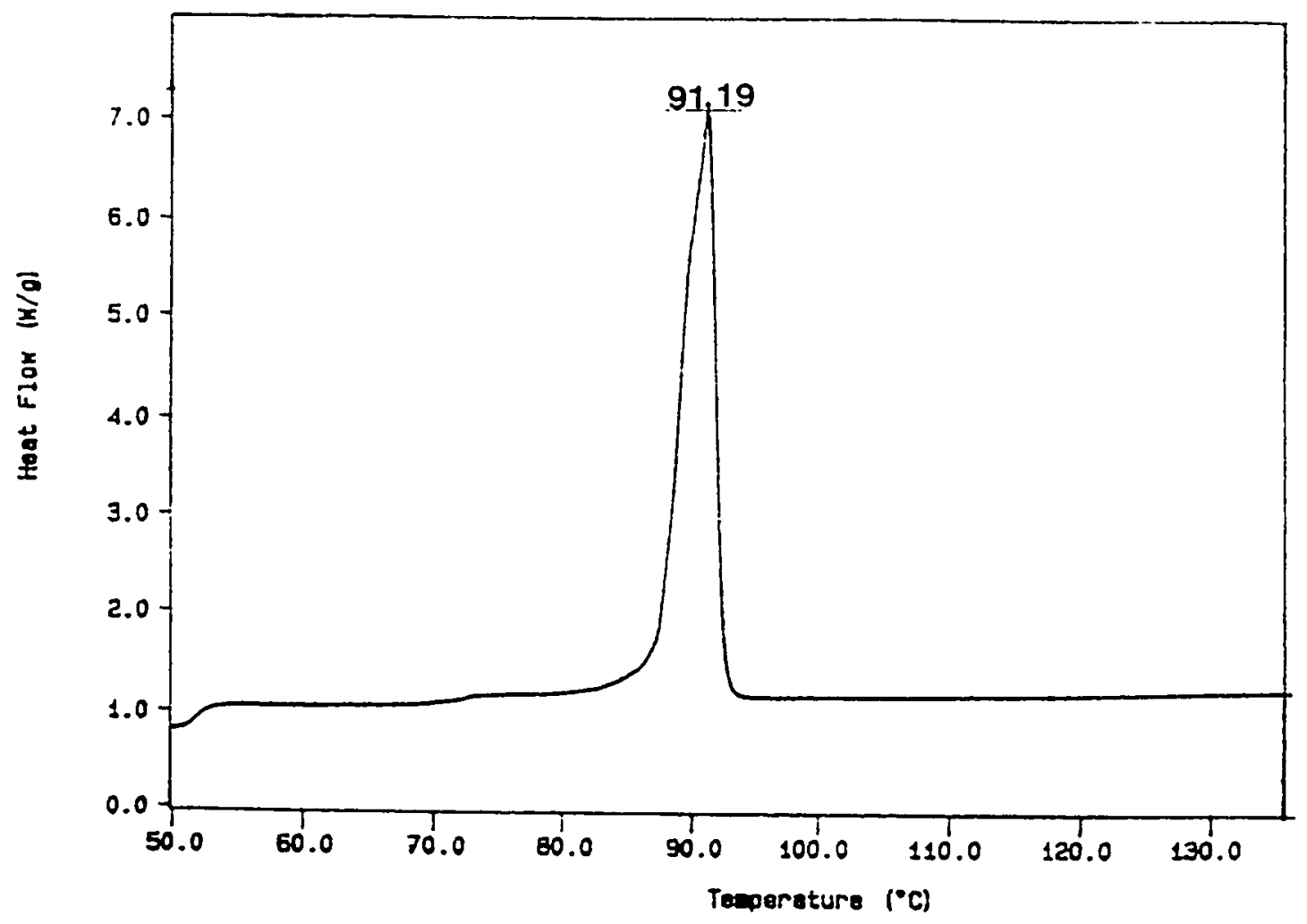

Figure 19. DSC thermogram of 4-methoxyphenyl 4-allyloxybenzoate in $\mathrm{N}_{2}$. 
inert atmosphere. It can be seen that there is a single endothermic transition at about 80.0 ${ }^{\circ} \mathrm{C}$. The endothermic transition of MPAB is at about $91.0{ }^{\circ} \mathrm{C}$. Due to the ordered structure of liquid crystals which are used as stationary phases in chromatography, we might expect this same behavior to be seen in the bonded species. As described in previous papers [5,14], DSC has proved that MPAB develops liquid crystalline behavior when bonded to polysiloxanes, but similar results were not obtained on porous silica. The results are shown in Figure 20. A broad transition can be observed in curve B, but no liquid crystalline behavior is seen. Similarly in curve A, no transitions can be observed for cholesteryl 10-undecenoate. It is not easy to explain these observations in terms of a ordered structure on the surface. It is possible that either the liquid crystal state is not obtained or that it can not be measured with our instrument. The behavior of the olefin and silica in the presence of oxygen are illustrated in Figure 21. In curve A, an exothermic peak at $450^{\circ} \mathrm{C}$ indicates the oxidative degradation of silane species into silanol groups. After bonding, the peak at $450^{\circ} \mathrm{C}$ disappears, and two other exothermic peaks are found at about 350 and $400{ }^{\circ} \mathrm{C}$, as shown in curve $\mathrm{B}$ and $\mathrm{C}$ for cholesteryl 10-undecenoate and MPAB, respectively. These changes confirm the success of the bonding reaction.

\subsection{Stability studies}

The stability of a stationary phase is an important factor in producing a good column. The elemental carbon on the surface was used to evaluate the amount of remaining bonded ligand in order to estimate the extent of bonded-phase deterioration. Surface coverage was used to evaluate liquid crystal bonded phase performance in terms of hydrolytic 


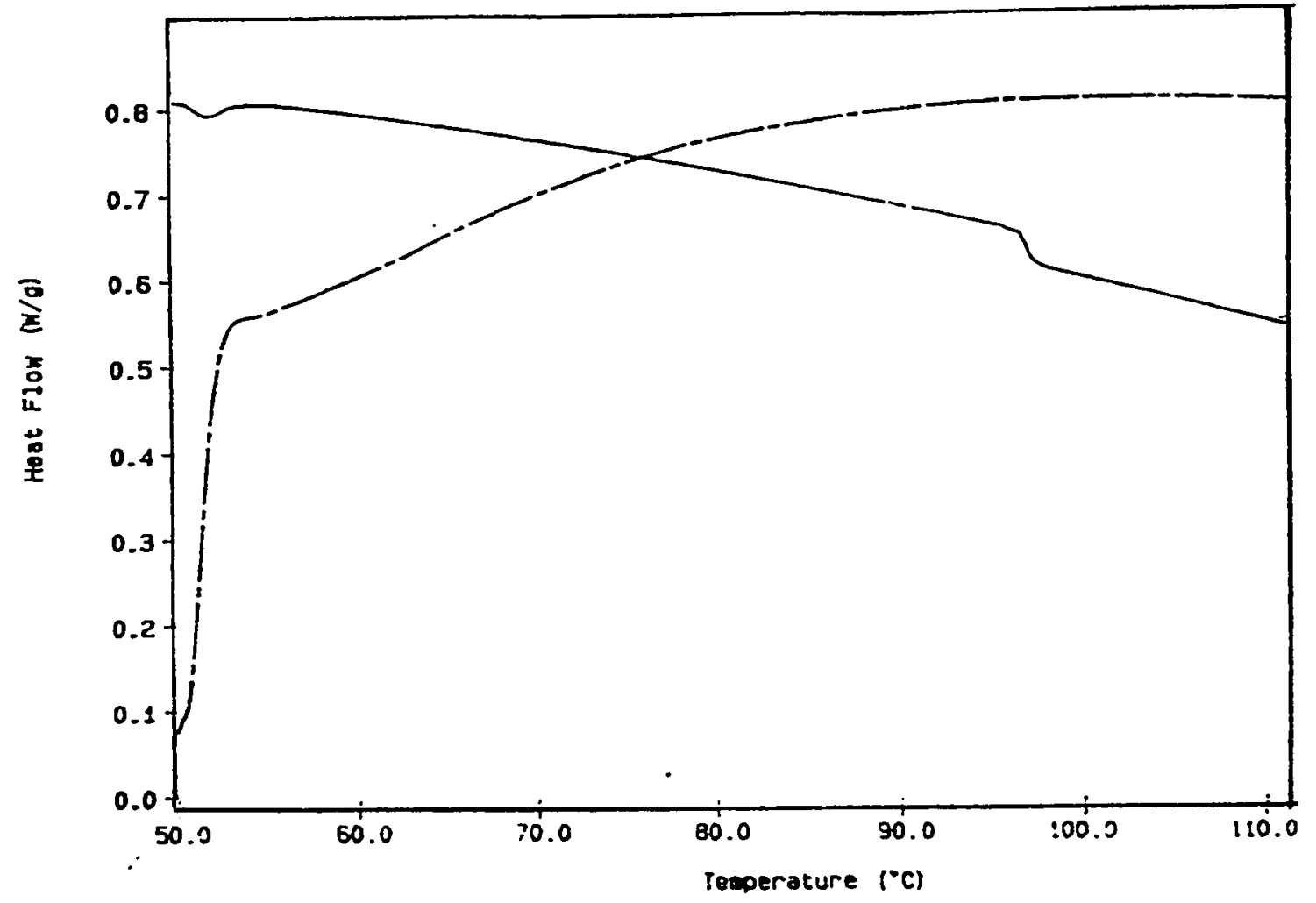

Figure 20. DSC thermogram of hydride silica bonded with (A) cholesteryl 10undecenoate and (B) 4-methoxyphenyl 4-allyloxybenzoate in $\mathrm{N}_{2}$. 


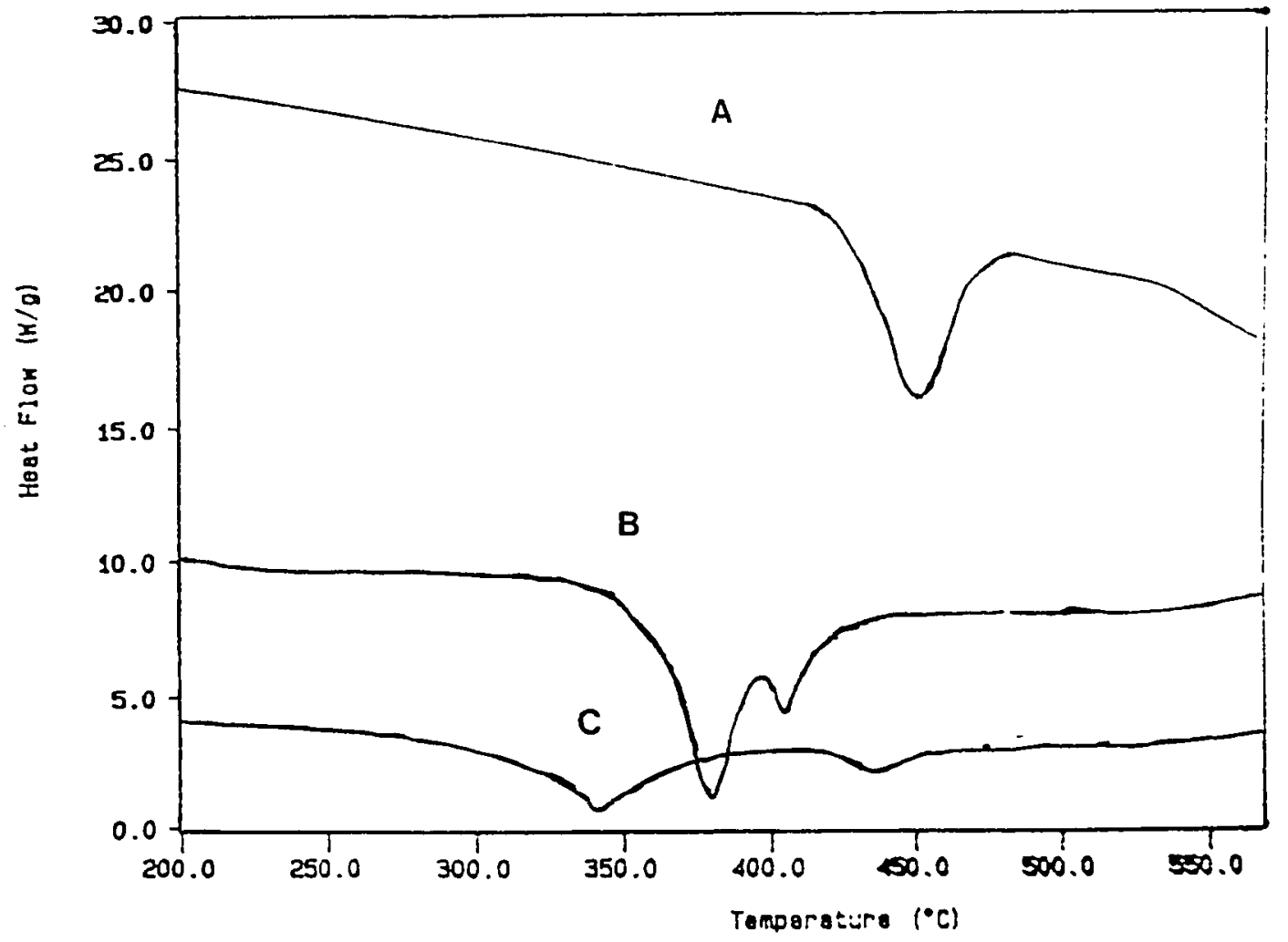

Figure 21. DSC thermogram of silica hydride (A) and after bonding with (B) cholesteryl 10-undecenoate and (C) 4-methoxyphenyl 4-allyloxybenzoate in $\mathrm{O}_{2}$. 
stability under solvent, water, and different $\mathrm{pH}$ buffer conditions, which are relative to separation procedures in HPLC.

pH test. In most silica-based supports, the mobile phase $\mathrm{pH}$ range is limited from 2 to 8 due to the hydrolysis of silica. It is necessary to test the stability of a bonded phase in this $\mathrm{pH}$ range for examining its potential use as a stationary phase. Table 4 presents the results of the stability studies of cholesteryl 10-undec noate bonded on silica at both high and low $\mathrm{pH}$ values $(\mathrm{pH}=7.96$ and 2.87$)$. The close similarity of the results obtained in different $\mathrm{pH}$ buffers after four days indicate that this bonded phase exhibits good conformity at both high and low $\mathrm{pH}$ values. As expected, after $\mathrm{pH}$ testing the bonded material gave the same hydrosilylation product for cholesteryl 10-undecenoate. Partial DRIFT spectrum shows typical results for cholesteryl 10-undecenoate bonded to silica at both $\mathrm{pH}$ buffer solutions (Figure 22). Identical peaks are observed at $2260 \mathrm{~cm}^{-1}$ for Si-H bend, at $3080 \mathrm{~cm}^{-1}$ for $=\mathrm{C}-\mathrm{H}$ bends, and at $3000-2800 \mathrm{~cm}^{-1}$ for aliphatic C-H stretching. In curve B, a decrease of the peak at $2260 \mathrm{~cm}^{-1}$ has been shown. The result may be from a reaction between $\mathrm{Si}-\mathrm{H}$ groups on silica surface and $-\mathrm{OH}$ groups in the high $\mathrm{pH}$ buffer solution. There is an about a $20 \%$ rate of degradation of the surface coverage between pre- and post- $\mathrm{pH}$ testing as shown in Table 4 . The loss may be due to cleavage of bonded cholesteryl 10-undecenoate molecules or from removal of unbounded material adsorbed on the surface.

Solvent test. The most common organic solvents used in HPLC as mobile phases are methanol and acetonitrile. Figure 23 shows the result of placing cholesteryl 10undecenoate bonded material in a mixture solvent containing the equivalent volumes of 


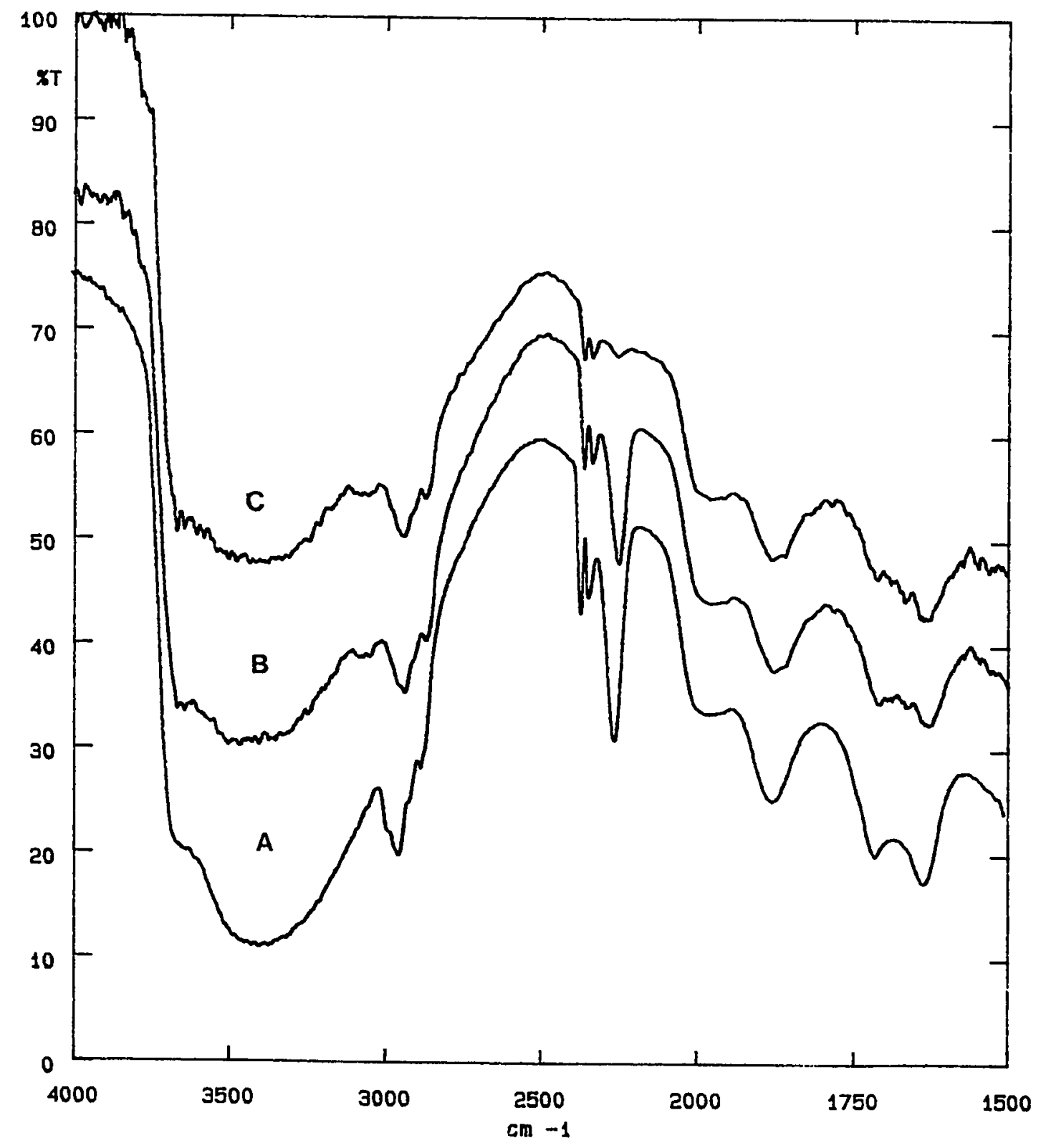

Figure 22. Partial DRIFT spectra of hydride silica bonded with cholesteryl 10-undecenoate (A) and in (B) $\mathrm{pH}=2.87$ and (C) $\mathrm{pH}=7.96$. 
Table 4. Effect of pH to Surface Coverage for Cholesteryl 10-Undecenoate Bonded to Hydride Silica

\begin{tabular}{|c|c|c|c|c|}
\hline \multirow[t]{2}{*}{ Buffer $^{a}$ pH } & \multicolumn{2}{|c|}{ Corrected Carbon (\%) } & \multicolumn{2}{|c|}{ Surface Coverage $\left(\mu \mathrm{mol} / \mathrm{m}^{2}\right)$} \\
\hline & Ori. ${ }^{*}$ & Test $* *$ & Ori. ${ }^{*}$ & Test ** \\
\hline 2.87 & 4.31 & 3.30 & 0.91 & 0.71 \\
\hline 7.96 & 4.31 & 3.26 & 0.91 & 0.70 \\
\hline
\end{tabular}

* Data from cholesteryl 10-undecenoate bonded on silica at $100{ }^{\circ} \mathrm{C}$ for 96 hours before pH testing

** Data from $\mathrm{pH}$ testing for four days by stirring

a - Buffer solution from $0.2 \mathrm{M} \mathrm{NaOH}$ added to a stock solution of $0.04 \mathrm{M}$ acetic, $0.04 \mathrm{M} \mathrm{H}_{3} \mathrm{PO}_{4}$ and $0.04 \mathrm{M}$ boric acid. 


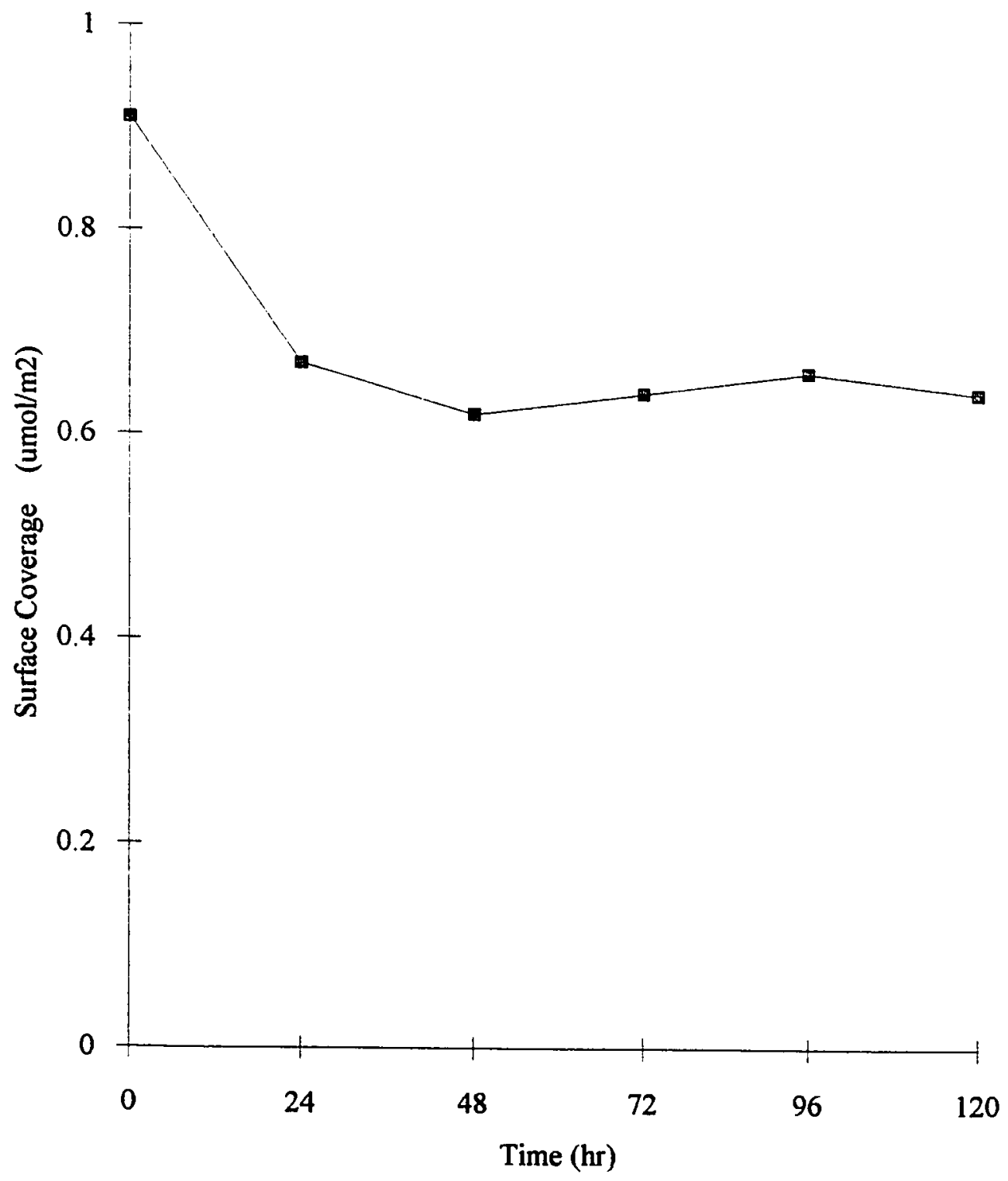

Figure 23. Surface coverage of cholesteryl 10-undecenoate-bonded hydride silica as a function of hydrolysis time in solvent testing during the room temperature. The solvent is equivalent volumes methanol and acetonitrile. 
methanol and acetonitrile. It should be noted that the surface coverage has changed during the early stage. However, a DRIFT analysis of the bonded phase indicates that the spectral properties of the material did not change from those observed in curve $A$ of Figure 24. At the end of the test, the bonded product had lost about $20 \%$ of its initial coverage [Fig. 23]. This is possibly due to detachments of some unreacted cholesteryl 10undeceate molecules absorbed on the surface as mention above or from the cleavage of bonded cholesteryl 10-undecenoate molecules. It should also be noticed that the major loss occurs during the early period of the hydrolysis, which is similar to the observations of Sandoval [32] when monitoring the hydrolytic stability of the Si-C bond. But it does indicate that some of the bonded compound is stable with solvent during long term test in which surface coverage did not significantly change after the critical decrease.

Water test. Water is always used as a component of the mobile phase in reversephase chromatography. A sample of cholesteryl 10-undecenoate bonded to silica was subjected to prolonged exposure to water. The DRIFT spectrum of silica bonded with cholesteryl 10-undecenoate after the hydrolysis testing for 120 hours in water at the room temperature is shown in Figure 24 (curve B). After water testing the bonded phase still has the same spectral features that are present before prolonged exposure to water. The decline of the Si-H stretching band at $2260 \mathrm{~cm}^{-1}$ may be due to the reaction between the $-\mathrm{OH}$ groups of water molecules and the $-\mathrm{H}$ groups on the residual Si-H species. The plot in Figure 25 clearly shows that a small loss of surface coverage occurs during the early stages of the long-term hydrolysis but that the amount is less than about $20 \%$ of its 


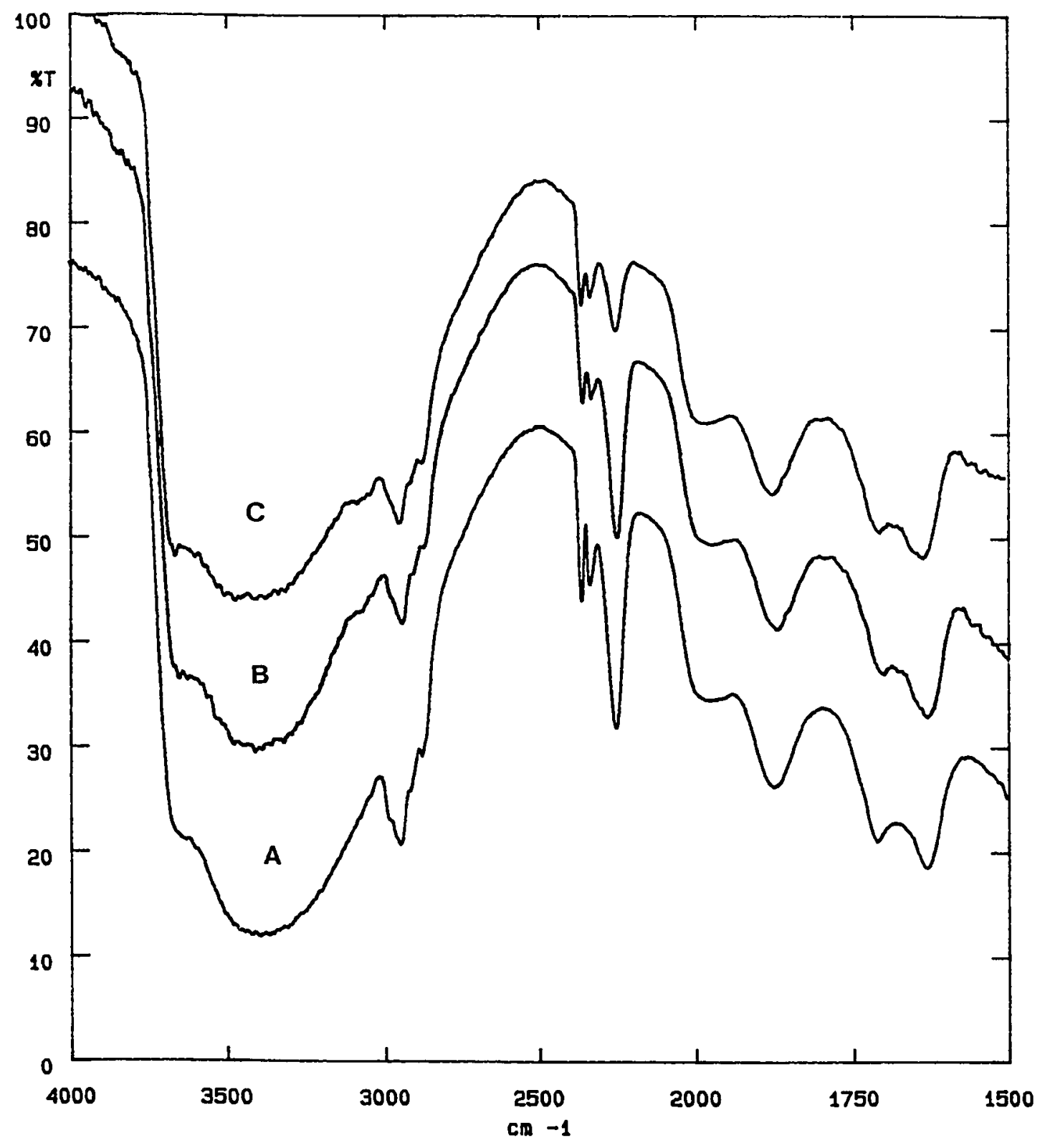

Figure 24. Partial DRIFT spectra of hydride silica bonded with cholesteryl 10undecenoate (A) after the hydrolysis testing for 120 hours in (B) methanol and acetonitrile and $(C)$ water. 


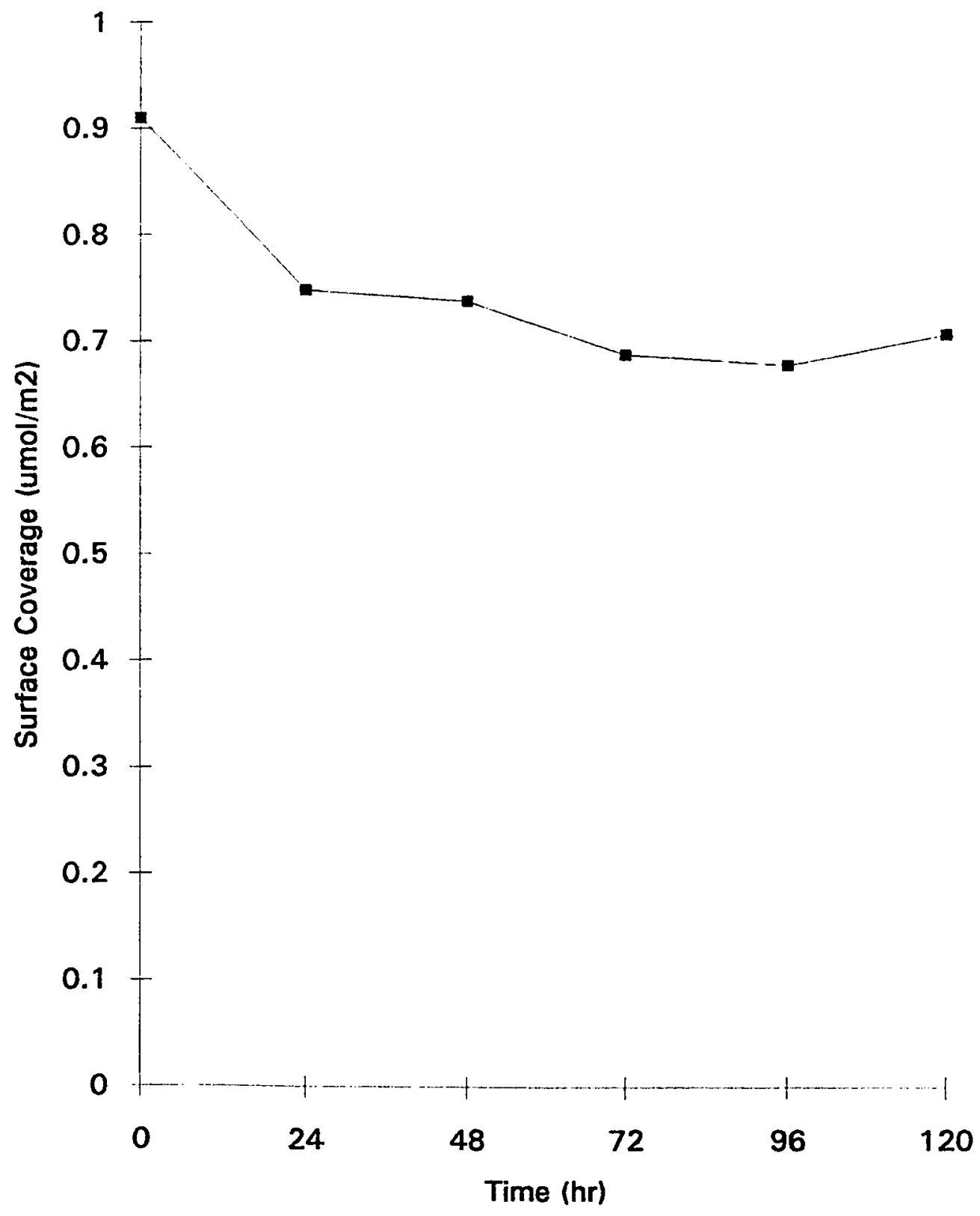

Figure 25. Surface coverage of cholesteryl 10-undecanoate-bonded silica as a function of hydrolysis time in water. 
starting alkyl load. The reason for such degradation of the bonded phase is the same as above.

\subsection{HPLC evaluation}

Selectivity of the bonding of liquid crystals to silica as the stationary phase appears to be mainly based on molecular shape [30]. PAHs (polycyclic aromatic hydrocarbons) have been used as test solutes to help elucidate the separation mechanism in reverse-phase chromatography due to both potential practical applications and the fact that they possess a variety of structural forms ( high degree of planarity). The chromatogram of PAHs on cholesteryl 10-undecenoate bonded to silica is shown in Figure 26. The three compounds (phenanthro[3,4-c]phenanthrene, benzo[a]pyrene, and tetrabenzonaphthalene) have been separated successfully by using acetonitrile (ACN) $90 \%$ / water $10 \%$ as the mobile phase at $1.0 \mathrm{ml} / \mathrm{min}$-flow rate. A mixture of sixteen PAH compounds was tested and the results are shown in Figure 27. Eleven peaks were obtained with an acetonitrile 35\%/ water $65 \%$ for 2 min., followed by a linear gradient to $100 \% \mathrm{ACN}$ in $14 \mathrm{~min}$. Because there are many factors that affect the separation efficiency, the separation could be optimized further by changing mobile phase, composition and gradient, time. But there is no doubt that cholesteryl 10-undecenoate bonded to silica hydride has the potential to be used as a stationary phase. 


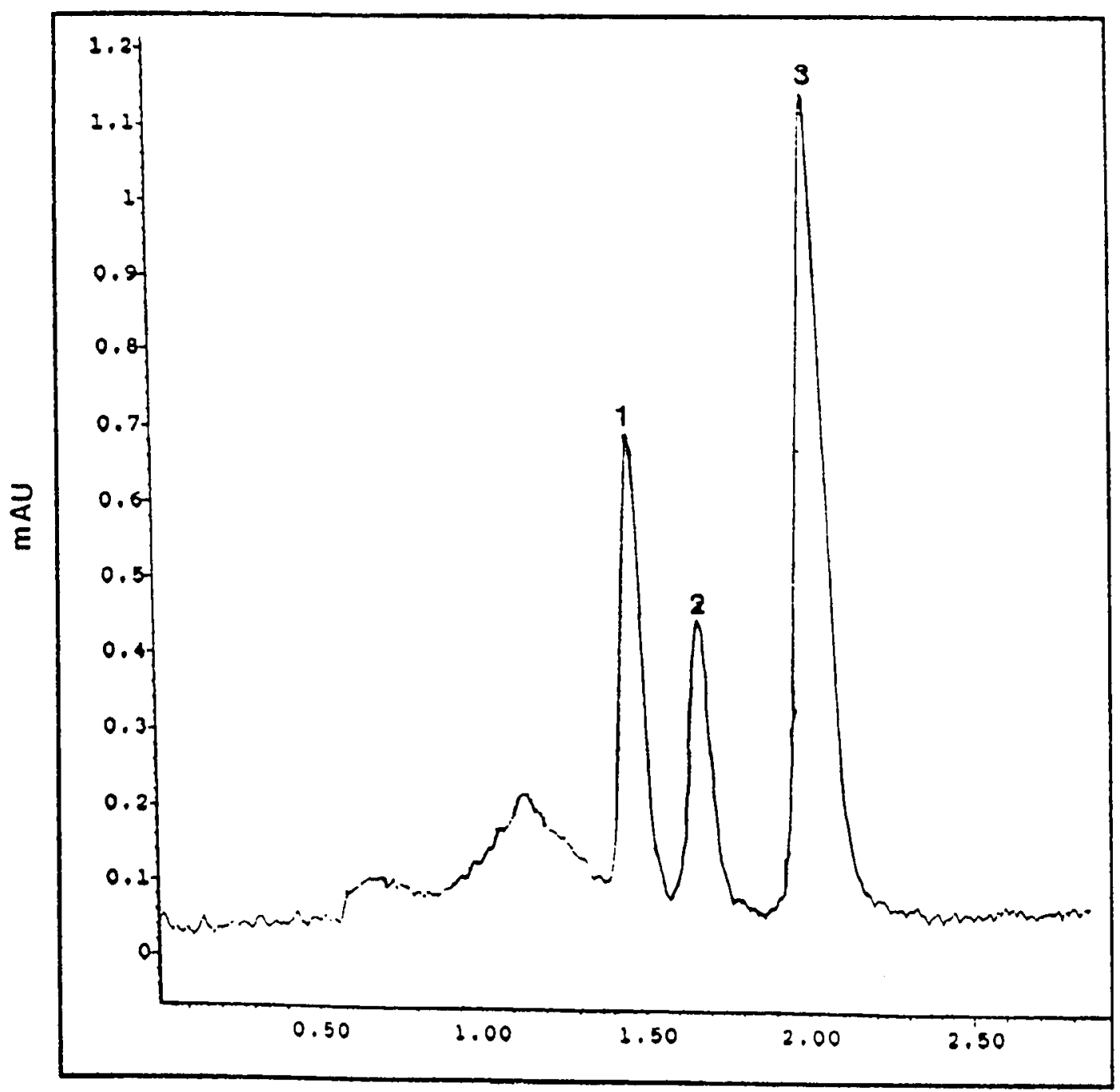

Time

Figure 26. Chromatogram of the separation of three PAH compounds on the cholesteryl 10-undecanoate-bonded silica phase in HPLC. $1=\mathrm{PhPh}, 2=\mathrm{BaN}$, and $3=\mathrm{TBN}$. Condition: room temperature; acetonitrile / water (90:10) mobile phase; $\operatorname{Sig}=254.4 \mathrm{~nm}$, $\operatorname{Ref}=350.8 \mathrm{~nm} ; 1.0 \mathrm{~mL} / \mathrm{min}$ flow rate. 


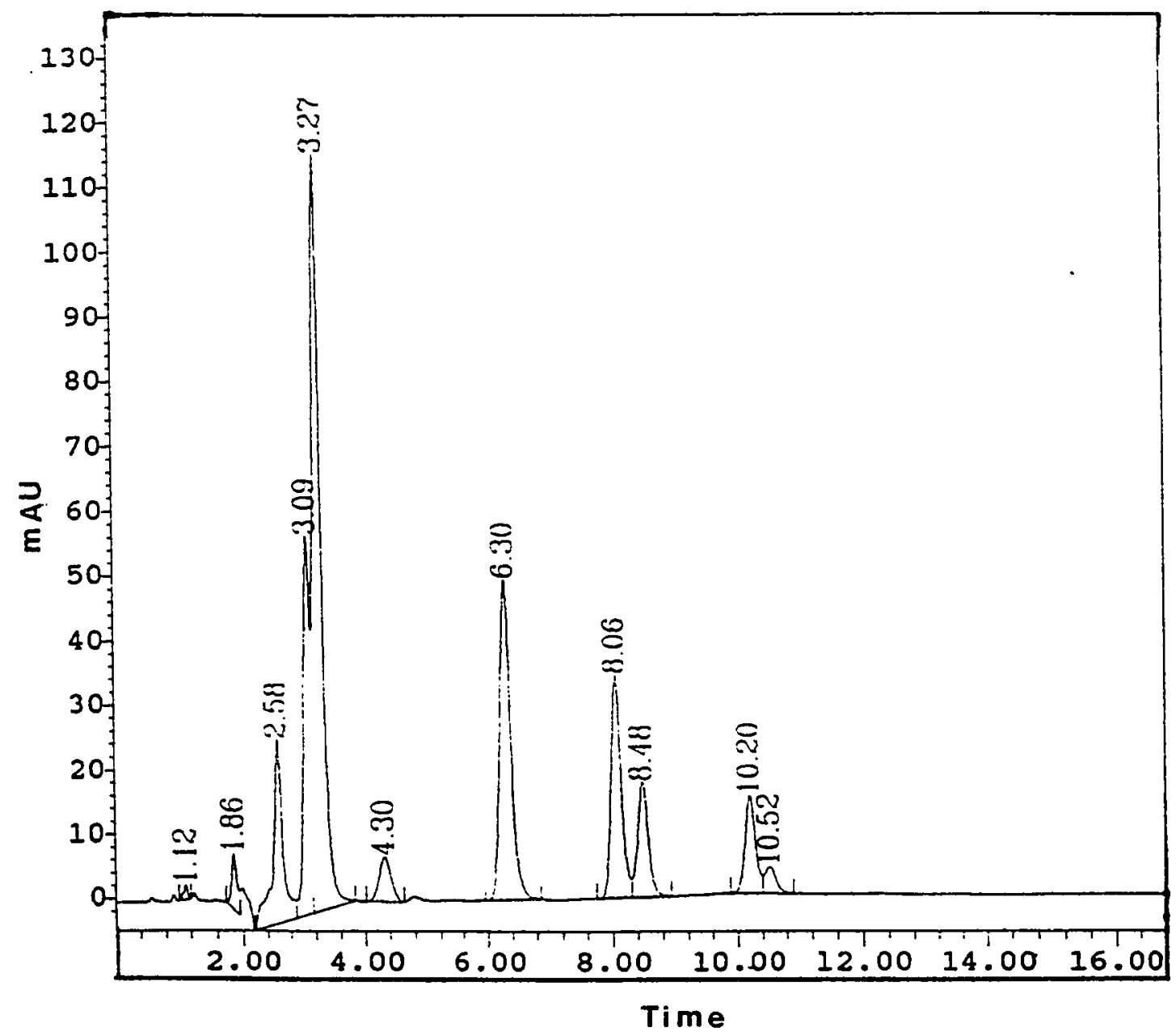

Figure 27. Chromatogram of the separation of sixteen PAH compounds on cholesteryl 10-undecanoate-bonded silica phase in HPLC. Conditions: room temperature; mobile phase, $35 \%$ acetonitrile / $65 \%$ water over 2 min., then linear gradient to $100 \%$ acetonitrile in $14 \mathrm{~min}$.; $\mathrm{Sig}=254.4 \mathrm{~nm}, \operatorname{Ref}=350.8 \mathrm{~nm}$; flow rate, $1.0 \mathrm{~mL} / \mathrm{min}$. 


\section{CONCLUSION}

A new stationary phase for HPLC has been developed by bonding a liquid crystalline compound to silica and used for the separation of polyaromatic hydrocarbons. The method showed improved alkyl coverage (to about $1.3 \mu \mathrm{mol} / \mathrm{m}^{2}$ ) and exhibited reasonable hydrolytic stability toward several mobile phases. The new bonded phase permits the use over wider $\mathrm{pH}$ intervals.

Besides improving surface coverage by changing the bonding procedure through variables, such as catalyst, solvent, and temperature, the extension of this work should focus on the investigation of the chromatographic analysis for separations of materials such as polyaromatic hydrocarbons, chiral compounds and biological materials. 


\section{REFERENCES}

1. Kelkar, H; Winterscheiàt, ẅ. Anal. Chem. 1960, 1, 220.

2. Dewar, M. J. S.; Schroeder, J. P. J. Am. Chem. Soc. 1964, 86, 5235.

3. Cook, L. E.; Sherman, P. L. Anal. Chem. 1974, f6, 122.

4. Janini, G. M.; Zeilinski, W. L. Anal. Chem. 1976, $48,809$.

5. Apfel, M. A.; Finkelman, H.;.Janini, G. M.; Laub, R. J; Luhmann, B.H.; Price, A.; Roberts W. C.; Shaw, T. J. Anal. Chem. 1985, 57, 651-658.

6. Lu, P. Z.; Zhang, Y. HPLC and Expert System, Science Publishers, Liao-Ning, P R China, 1993.

7. Sander, L. C.; Wise, S. A. CRC Crit. Rev. Anal. Chem. 1987, 18, 299.

8. Nawrocki, J. Chromatographia, 1991, 31, 177

9. Dorsey, John. G.; Cooper, W. T. Anal. Chem. 1994, 66, 857A.

10. Pleuddemann, E. P. Silane Coupling Agents, Plenum, N. Y., 1982.

11. Sandoval, J. E.; Pesek, J. J. Anal. Chem. 1989, 61, 2067.

12. Pawlenko, S. Organosilicon Chem. (de Groyter, Berlin) 1988.

13. Van den Driest, P. J.; Richie, H. J.; Rose, S. LC-GC 1988, 6, 124.

14. Pesek, J. J.; Graham, J. A. Anal. Chem. 1977, 49, 133

15. Unger, V. U.; Thomas, W.; Adrian, P. Kdloid-2, 1973, 251, 45.

16. Chu, C. J.; Jonsson, E. J.; Anvinen, M.; Pesek, J. J.; Sandoval, J. E. Anal. Chem. $1993,65,808-816$.

17. Shah, S. MS thesis, San Jose State University, 1991. 
18. De Jeu, W.H. "Physical properties of liquid crystalline materials", Gordon and Breach science publishers 1943.

19. Meier, G.; Sackmann, E.; Grabmaier, J. G. "Applications of liquid crystals", New York, 1975.

20. Collings, P. J. “Liquid crystals", New Jersey, 1990.

21. Witkiewicz, Z. J. Chromatogr. 1982, 251, 311.

22. Wise, S. A.; Sander, L. C. J. High Resolut, Chromatogr. Chromatogr. Commun. $1985,8,248$.

23. Witkiwicz, Z.; Rudnicku, I.; Szulc, J.; Dabrowski, R. J. Chromatogr. 1984, 294, 127-137.

24. Taylor, P. J.; Sherman, P. L. L. Liq. Chromatogr. 1980, 3, 21.

25. Aratskova, A.A.; Vetrova, Z. P.; Yashin, Y. I. J. Chromat. 1986, 365, 27-30.

26. Pesek, J. J.; Vidensek, M. A.; Miller, M. J.Chromatogr. 1991, 556, 373-381.

27. Pesek, J. J.; Cash, T. Chromatographia, 1989, 27, 559.

28. Berendsen; De Galan, J. Liquid Chromatographia, 1978, I(5), 561-568.

29. Pesek, J. J.; Williamen, E. J. Trends in Analytical Chem. 1992, II(7), 259-264.

30. Speier, J. L. Organoment. Chem. 1979, 17, 401.

31. Kinkel, J. N.; Unger, K. K. J. Chromatogr. 1984, 316, 193.

32. Sandoval, J. E.; Pesek, J. J. Anal. Chem. 1991, 63, 2634-2641. 